\title{
Analytical Solution of Tidal Loading Effect in a Submarine Leaky Confined Aquifer System
}

\author{
Zongzhong Song, ${ }^{1}$ Hailong Li $\mathbb{D},{ }^{2,3}$ Qian Ma, ${ }^{4}$ Chunmiao Zheng, ${ }^{2,3}$ Jiu Jimmy Jiao, ${ }^{5}$ \\ and Shaohong $\mathbf{L i}^{6}$ \\ ${ }^{1}$ Beijing Guohuan Tsinghua Environmental Engineering Design \& Research Institute Co. Ltd., Beijing 100084, China \\ ${ }^{2}$ State Environmental Protection Key Laboratory of Integrated Surface Water-Groundwater Pollution Control, School of \\ Environmental Science and Engineering, Southern University of Science and Technology, Shenzhen 518055, China \\ ${ }^{3}$ Guangdong Provincial Key Laboratory of Soil and Groundwater Pollution Control, School of Environmental Science \\ and Engineering, Southern University of Science and Technology, Shenzhen 518055, China \\ ${ }^{4}$ Tianjin University, Library, 300350, China \\ ${ }^{5}$ Department of Earth Science, University of Hong Kong, Hong Kong, China \\ ${ }^{6}$ State Key Laboratory of Biogeology and Environmental Geology and School of Water Resources and Environment, China University \\ of Geosciences-Beijing, Beijing 100083, China
}

Correspondence should be addressed to Hailong Li; lihailong@sustc.edu.cn

Received 23 February 2019; Revised 18 May 2019; Accepted 30 May 2019; Published 20 June 2019

Guest Editor: Leanne Morgan

Copyright (c) 2019 Zongzhong Song et al. This is an open access article distributed under the Creative Commons Attribution License, which permits unrestricted use, distribution, and reproduction in any medium, provided the original work is properly cited.

\begin{abstract}
Although there are many existing analytical studies of tidal groundwater level fluctuations in coastal aquifer systems, few of them focus on an offshore submarine aquifer. Here, we consider tidal groundwater head fluctuations in a submarine leaky confined aquifer overlain by a semipermeable seabed. Both the seabed and the confined aquifer are assumed to extend horizontally infinitely. A one-dimensional mathematical model is established to describe the problem, and the analytical solution is derived. The impacts of the tidal loading efficiency, hydraulic conductivity and elastic storage of the semipermeable layer and aquifer on the groundwater head fluctuations in the aquifer system are analyzed and discussed. Solution analyses indicated that tidal loading effects tend to enhance the amplitude of the tidal groundwater fluctuation in the confined aquifer system and to reduce the phase shift between the groundwater head and the sea tide fluctuations.
\end{abstract}

\section{Introduction}

The study of tidal groundwater level fluctuations in coastal aquifer systems is beneficial to solving various coast environmental problems. Many analytical solutions have been derived in this field since the 1950s. Jacob [1] and Ferris [2] firstly derived analytical solutions to describe the tideinduced groundwater fluctuation in a confined aquifer which ends at the coastline. The equations have been widely used in field survey and aquifer parameter estimation in coastal areas (e.g., [3-9]). Since then, various analytical solutions related to tidal head fluctuations have been derived for coastal confined aquifers. Van der Kamp [10] investigated the tidal ground- water fluctuation in an aquifer with an impermeable roof extending seaward and landward infinitely. $\mathrm{Li}$ and Chen [11] considered a coastal confined aquifer with an impermeable roof extending under the sea for a certain length, neglecting the vertical leakage. Jiao and Tang [12] discussed the tide-induced groundwater head fluctuation in an onshore multilayered coastal aquifer system neglecting the elastic storage of the semipermeable layer. Based on Jiao and Tang's study [12], Li and Jiao [13] took into account the elastic storage of the semipermeable layer, and they [14] considered a leaky aquifer with the roof extending under the sea. Jeng et al. [15] considered the interference of the tidal groundwater level fluctuations in a multilayered aquifer system with the 


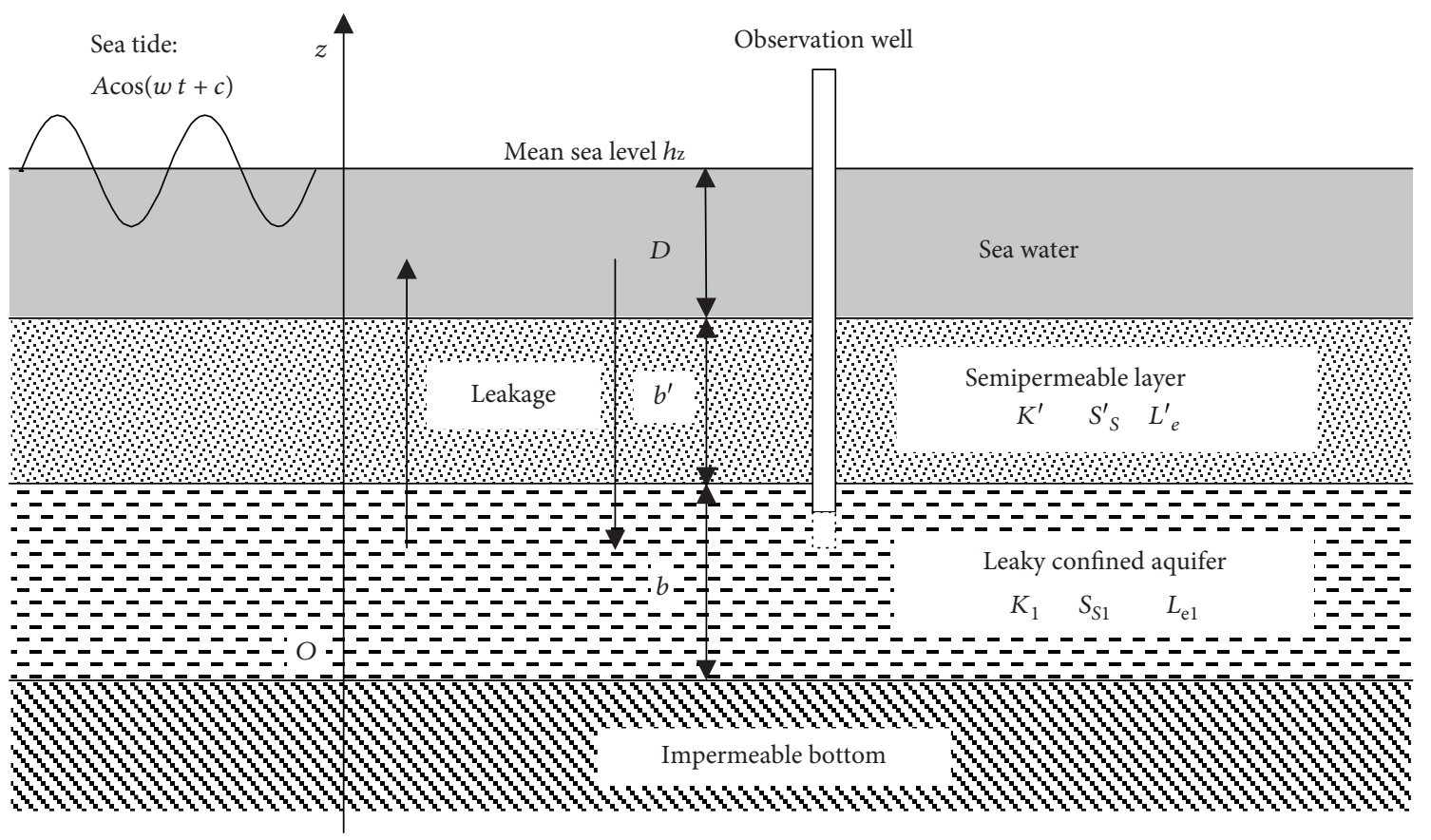

Figure 1: Schematic of a submarine leaky confined aquifer system.

leakage of a semipermeable layer considered. Li and Jiao [16] improved Jeng et al.'s work [15] in the sense that both the leakage and elastic storage of the leaky layer are considered. Li et al. [17] considered a coastal multilayered aquifer system with the confined aquifer and its semipermeable roof extending infinitely under the sea. All the effects related to the semipermeable layer such as the elastic storage, the leakage, and the tidal loading efficiency were taken into account. Guarracino et al. [18] derived an analytical solution to describe the tide-induced head fluctuation in an aquifer system that extends a finite distance under the sea, with which the extending length may be estimated from groundwater head measurement. Wang et al. [19] presented an analytical study on the loading effect of the water table variations in a coastal aquifer system consisting of an unconfined aquifer, a confined aquifer, and an impermeable layer between them.

Due to the tidal fluctuations, the total weight of the pore water (the onshore part) or sea water (the offshore part) in/overlying the aquifers will vary accordingly, which in turn can cause a considerable tidal loading effect on the groundwater flow. Many researchers [11, 14, 17-20] considered the tidal loading effect in their analytical studies, whereas almost all of the existing studies of tide-induced groundwater fluctuations focus on the tide-induced groundwater level fluctuation in onshore aquifer. Although there are some analytical solutions of tide-induced groundwater fluctuations in the submarine confined aquifer system in the offshore part (e.g., [14, 17, $18]$ ), the dependency of the tide-induced groundwater head fluctuation in the offshore submarine aquifer on the model parameter was not analyzed or discussed. The offshore submarine aquifers are important both in water resources and in marine environments (e.g., [21-26]). Therefore, the study of the groundwater flow in offshore submarine aquifer systems is necessary and important.

This paper considered a submarine leaky confined aquifer system with the confined aquifer and its semipermeable roof extending infinitely under the sea. All effects related to the submarine leaky confined aquifer system such as the elastic storage, the hydraulic conductivity, and the tidal loading efficiency were taken into account. The mathematic model was given, and the analytical solution was derived. The influences of the tidal loading efficiency, the elastic storage, and the hydraulic conductivity on the tidal groundwater head fluctuations in the confined aquifer and in the seabed were analyzed and discussed.

\section{Mathematical Model and Analytical Solution}

2.1. Mathematical Model. The configuration of a submarine leaky confined aquifer system is shown in Figure 1. The aquifer is overlain by a semipermeable seabed aquifer/layer. Both the semipermeable seabed and the confined aquifer are assumed to extend horizontally infinitely. This assumption is reasonable when the considered offshore submarine aquifer is far enough from the coastline. There are even many offshore freshwater submarine aquifers extending in all horizontal directions extensively and very far from the coastline [22-26]. In addition, several existing analytical studies assume that the coastal aquifer systems extend seaward infinitely (e.g., $[10,14,17,27])$. A vertically one-dimensional mathematical model is used to describe the problem.

Let the $z$ axis be positive upwards (Figure 1). All the layers are homogeneous and with constant thickness. Based on these assumptions and the theories of leaky, elastic aquifers proposed by Hantush and Jacob [28] and Jacob [1], the 
mathematical model to describe the groundwater fluctuations in Figure 1 is as follows:

$$
\begin{aligned}
S_{S} \frac{\partial H}{\partial t}=K \frac{\partial^{2} H}{\partial z^{2}}+S_{S} L_{e} \frac{d H_{S}}{d t}, & -\infty<t<+\infty, 0< \\
-\infty\left(b+b^{\prime}, t\right) & =H_{S}(t)=r_{\rho} A \cos (\omega t+c), \\
\lim _{z \downarrow b} H(z, t) & =\lim _{z \uparrow b} H(z, t), \\
\lim _{z \downarrow b} K^{\prime} \frac{\partial H}{\partial Z} & =\lim _{z \uparrow b} K_{1} \frac{\partial H}{\partial z}, \\
\left.\frac{\partial H}{\partial z}\right|_{z=0} & =0,
\end{aligned}
$$$$
-\infty<t<+\infty, 0<z<b+b^{\prime}, z \neq b,
$$

where $H(z, t), S_{S}$, and $K$ are the hydraulic head [L], specific storage $\left[\mathrm{L}^{-1}\right]$, and vertical hydraulic conductivity $\left[\mathrm{LT}^{-1}\right]$ of the semipermeable layer or the aquifer, respectively; $L_{e}$ is the tidal loading efficiency (dimensionless) $[--] ; r_{\rho}$ is the density ratio (dimensionless) of the seawater to the freshwater with the range from 1.02 to $1.03 ; b$ and $b^{\prime}$ are the thicknesses [L] of the aquifer and the semipermeable layer, respectively; $S_{S}$ takes the value of $S_{S}^{\prime}$ in the semipermeable layer and $S_{S 1}$ in the confined aquifer; $K$ equals $K^{\prime}$ in the semipermeable layer and $K_{1}$ in the confined aquifer; $H_{S}(t)$ is the hydraulic head of the sea tide [L]; $A$ is the amplitude [L] of the tidal fluctuation; $\omega$ is the angular velocity (or frequency) $\left[\mathrm{T}^{-1}\right]$ of tide and equals $2 \pi / t_{0}$ with $t_{0}$ being the tidal period [T]; and $c$ is the phase shift (in radian). The bottom of the confined aquifer is set to be the datum of the system.

Equation (1) indicates that the groundwater level fluctuation in the submarine leaky confined aquifer is caused by its elastic compression and expansion due to the tidal loading rate of the sea water above seabed $\left(S_{S} L_{e}\left(d H_{s} / d t\right)\right)$, in addition to the tidal fluctuation at the seabed boundary $z=b+b^{\prime}$ as expressed by equation (2). Equations (3) and (4) are the continuity conditions of the hydraulic head and groundwater flux, respectively. Equation (5) states the no-flow boundary condition on the upper surface of the impermeable bottom.

2.2. Analytical Solution. In order to facilitate analysis, four parameters are introduced: the main aquifer's tidal propagation parameter $a\left[\mathrm{~L}^{-1}\right]$ defined as

$$
a=\sqrt{\frac{\omega S_{S 1}}{2 K_{1}}}
$$

the dimensionless thickness of the seabed defined as

$$
\theta=b^{\prime} \sqrt{\frac{\omega S_{S}^{\prime}}{2 K^{\prime}}}=\sqrt{\frac{s}{2 u}}
$$

where $s$ is the dimensionless storativity ratio and defined as

$$
s=\frac{S_{S}^{\prime} b^{\prime}}{S_{S 1} b}
$$

and the dimensionless leakage $u$ defined as

$$
u=\frac{K^{\prime}}{\omega S_{S 1} b b^{\prime}}
$$

The solution of boundary value problem (1), (2), (3), (4), and (5) is given by the following equations (see Appendix A for the derivation):

$$
\begin{aligned}
H(z, t)= & r_{\rho} A \operatorname{Re}[\exp (\mathrm{i} \omega t)\{C \cosh [(1+\mathrm{i}) a z] \\
& \left.\left.+L_{e 1}\right\}\right], \quad 0<z<b \\
H(z, t)= & r_{\rho} A \operatorname{Re}\left[\operatorname { e x p } ( \mathrm { i } \omega t ) \left\{C_{1} e^{((1+\mathrm{i}) \theta z) / b^{\prime}}\right.\right. \\
& \left.\left.+C_{2} e^{-((1+\mathrm{i}) \theta z) / b^{\prime}}+L_{e}^{\prime}\right\}\right], \quad b<z<b+b^{\prime} .
\end{aligned}
$$

The analytical solutions (10a) and (10b) of the groundwater heads $H(z, t)$ can be deformed as (see Appendix B for the derivation of the analytical solutions)

$$
H(z, t)=r_{\rho} A A_{r} \cos (\omega t-\varphi)
$$

where $A_{r}\left(L_{e 1}, L_{e}^{\prime}, a b, \theta, p, \tau, z\right)$ is the amplitude ratio and $\varphi\left(L_{e 1}, L_{e}^{\prime}, a b, \theta, p, \tau, z\right)$ is the comprehensive tidal phase shift in the aquifer defined as

$$
\begin{aligned}
& A_{r}\left(L_{e 1}, L_{e}^{\prime}, a b, \theta, p, \tau, z\right) \\
& \quad=\left|C \cosh [(1+\mathrm{i}) a z]+L_{e 1}\right|, \quad 0<z<b,
\end{aligned}
$$

$$
\begin{aligned}
A_{r} & \left(L_{e 1}, L_{e}^{\prime}, a b, \theta, p, \tau, z\right) \\
& =\left|C_{1} e^{((1+\mathrm{i}) \theta z) / b^{\prime}}+C_{2} e^{-((1+\mathrm{i}) \theta z) / b^{\prime}}+L_{e}^{\prime}\right|, \quad b<z<b+b^{\prime},
\end{aligned}
$$

$$
\begin{aligned}
& \varphi\left(L_{e 1}, L_{e}^{\prime}, a b, \theta, p, \tau, z\right) \\
& \quad=-\arg \left(C \cosh [(1+\mathrm{i}) a z]+L_{e 1}\right), \quad 0<z<b, \\
& \varphi\left(L_{e 1}, L_{e}^{\prime}, a b, \theta, p, \tau, z\right) \\
& \quad=-\arg \left(C_{1} e^{((1+\mathrm{i}) \theta z) / b^{\prime}}+C_{2} e^{-((1+\mathrm{i}) \theta z) / b^{\prime}}+L_{e}^{\prime}\right), \\
& b<z<b+b^{\prime} .
\end{aligned}
$$

The three parameters $C, C_{1}$, and $C_{2}$ are given by the following equations (see Appendix $\mathrm{C}$ for the derivation):

$$
C=\frac{C_{1} \exp [(1+\mathrm{i}) \tau \theta]+C_{2} \exp [-(1+\mathrm{i}) \tau \theta]+L_{e}^{\prime}-L_{e 1}}{\cosh [(1+\mathrm{i}) a b]}
$$


TABLE 1: Ranges of parameters $a b, \theta, p$, and $\tau$ in the leaky confined aquifer systems reported in the literature.

\begin{tabular}{lccccccccccc}
\hline & Leaky aquifer & \multicolumn{4}{c}{ Semipermeable layer } & \multicolumn{4}{c}{ Model parameters } \\
$K_{1}\left(\mathrm{~m} \cdot \mathrm{d}^{-1}\right)$ & $S_{S 1}\left(\times 10^{-6} \mathrm{~m}^{-1}\right)$ & $b(\mathrm{~m})$ & $K^{\prime}\left(\mathrm{m} \cdot \mathrm{d}^{-1}\right)$ & $S_{S}{ }^{\prime}\left(\times 10^{-4} \mathrm{~m}^{-1}\right)$ & $b^{\prime}(\mathrm{m})$ & $A b$ & $\theta$ & $p$ & $\tau$ & References \\
\hline 7.71 & 2.57 & 14 & 0.013 & 2.5 & 4 & 0.020 & 1.37 & $1.69 E-3$ & 3.50 & {$[31]$} \\
11.29 & 3.21 & 14 & 0.013 & $\mathrm{NA}$ & 4 & 0.018 & $\mathrm{NA}$ & $1.15 E-3$ & 3.50 & {$[32]$} \\
8.14 & 0.21 & 14 & 0.013 & 8.75 & 4 & 0.018 & 2.56 & $1.60 E-3$ & 3.50 & {$[32]$} \\
579.43 & 4.00 & 28 & 0.0016 & 3.30 & 9.1 & 0.017 & 10.15 & $2.76 E-6$ & 3.08 & {$[33]$} \\
579.43 & 4.00 & 28 & 0.0016 & 7.89 & 15.2 & 0.017 & 25.87 & $2.76 E-6$ & 1.84 & {$[33]$} \\
1.20 & 16.07 & 6.1 & 0.0082 & 13.33 & 3 & 0.055 & 2.98 & $6.83 E-3$ & 2.03 & {$[34]$} \\
45.81 & 5.63 & 16 & 0.0021 & 0.38 & 13.1 & 0.014 & 4.16 & $4.58 E-5$ & 1.22 & {$[35]$} \\
\hline
\end{tabular}

NA means that data are not available.

where

$$
\tau=\frac{b}{b^{\prime}}
$$

is the thickness ratio (dimensionless) and $C_{1}$ and $C_{2}$ are two complex constants determined by equations (A.4) and (A.5) and given by

$$
\begin{aligned}
C_{1}= & \frac{1}{\Delta}\left\{e ^ { - ( 1 + \mathrm { i } ) \tau \theta } \left[\tanh [(1+\boldsymbol{i}) a b]\left(L_{e}^{\prime}-L_{e 1}\right) e^{-(1+\mathrm{i}) \theta}\right.\right. \\
+ & \left.\left.\left(\frac{\theta p \tau}{a b}+\tanh [(1+\boldsymbol{i}) a b]\right)\left(1-L_{e}^{\prime}\right)\right]\right\}, \\
C_{2}= & \frac{1}{\Delta}\left\{e ^ { ( 1 + \mathrm { i } ) \tau \theta } \left[-\tanh [(1+\mathrm{i}) a b]\left(L_{e}^{\prime}-L_{e 1}\right) e^{(1+\mathrm{i}) \theta}\right.\right. \\
& \left.+\left(\frac{\theta p \tau}{a b}-\tanh [(1+\mathrm{i}) a b]\right)\left(1-L_{e}^{\prime}\right)\right]
\end{aligned}
$$

with

$$
\begin{aligned}
\Delta= & \frac{2 \theta p \tau}{a b} \cosh [(1+\mathrm{i}) \theta] \\
& +2 \tanh [(1+\mathrm{i}) a b] \sinh [(1+\mathrm{i}) \theta], \\
p= & \frac{K^{\prime}}{K_{1}} .
\end{aligned}
$$

\section{Discussion of the Solution}

3.1. Value Ranges of Model Parameters. The value ranges of dimensionless model parameters $a b, \theta, p$, and $\tau$ for the leaky confined aquifer system reported in the literature are shown in Table 1, according to the summarization of $\mathrm{Li}$ and Jiao ([13], Table 1). One can see that $a b$ ranges from 0.014 to $0.055, \theta$ from 1.37 to 25.87 , $p$ from $2.76 \times 10^{-6}$ to $6.83 \times$ $10^{-3}$, and $\tau$ from 1.22 to 3.50. Based on these data and other situations (for example, the thickness of the submarine confined aquifer could be up to several hundred meters), the ranges of the parameters in the following discussion will be chosen: $0.001 \sim 10$ for $a b, 0 \sim 100$ for $\theta, 1 \times 10^{-5} \sim 1 \times 10^{-1}$ for $p$, and $1 \sim 10$ for $\tau$.
The tidal loading efficiency $\left(L_{e}^{\prime}\right)$ in the semipermeable roof of the coastal confined aquifer system is usually very close to 1 [17]. So the value of $L_{e}^{\prime}$ will be fixed at 0.9 in the following discussion. Previous analytical studies and field surveys $[7,29,30]$ show that the range of the tidal loading efficiency $\left(L_{e 1}\right)$ in the confined aquifer changes from 0.05 to 1 .

\subsection{Comparison with Existing Solutions}

3.2.1. Case 1: Seabed without Elastic Storage $\left(S_{S}^{\prime} \rightarrow 0\right)$. When the elastic storage and loading efficiency of the seabed are close to zero $\left(S_{S}^{\prime} \rightarrow 0 ; L_{e}^{\prime} \rightarrow 0\right)$, a simpler analytical solution of the confined aquifer system can be obtained. In view of equation (7), one has $\theta \rightarrow 0$. For the confined aquifer, letting $L_{e}^{\prime} \rightarrow 0$ and $\theta \rightarrow 0$ in equation (13a) yields

$$
\begin{aligned}
\lim _{\theta \rightarrow 0} C= & \frac{1}{\cosh [(1+\mathrm{i}) a b]} \\
& \cdot\left\{\frac{u+(1+i) L_{e 1} \tanh [(1+i) a b] /(2 a b)}{u+(1+i) \tanh [(1+i) a b] /(2 a b)}-L_{e 1}\right\} .
\end{aligned}
$$

Letting $\theta \rightarrow 0$ in equations (12a) and (12c) yields

$$
\begin{aligned}
\lim _{\theta \rightarrow 0} A_{r}= & \mid \frac{\cosh [(1+i) a z]}{\cosh [(1+i) a b]} \\
& \cdot\left\{\frac{u+(1+i) L_{e 1} \tanh [(1+i) a b] /(2 a b)}{u+(1+i) \tanh [(1+i) a b] /(2 a b)}-L_{e 1}\right\}+L_{e 1} \mid,
\end{aligned}
$$

$$
\begin{aligned}
\lim _{\theta \rightarrow 0} \varphi= & -\arg \left(\frac{\cosh [(1+i) a z]}{\cosh [(1+i) a b]}\right. \\
& \left.\cdot\left\{\frac{u+(1+i) L_{e 1} \tanh [(1+i) a b] /(2 a b)}{u+(1+i) \tanh [(1+i) a b] /(2 a b)}-L_{e 1}\right\}+L_{e 1}\right) .
\end{aligned}
$$

Assuming $a b \rightarrow 0(a z \rightarrow 0)$ in equations (14b) and (14c) yields 


$$
\begin{aligned}
\lim _{a b \rightarrow 0} A_{r} & =\left|\frac{u+(1+i) L_{e 1} \tanh [(1+i) a b] /(2 a b)}{u+(1+i) \tanh [(1+i) a b] /(2 a b)}\right| \\
& =\left|\frac{u+(1+i) L_{e 1}(1+i) / 2}{u+(1+i)(1+i) / 2}\right|, \\
\lim _{\theta \rightarrow 0} \phi & =-\arg \left(\frac{u+(1+i) L_{e 1} \tanh [(1+i) a b] /(2 a b)}{u+(1+i) \tanh [(1+i) a b] /(2 a b)}\right) \\
& =-\arg \left(\frac{u+(1+i) L_{e 1}(1+i) / 2}{u+(1+i)(1+i) / 2}\right)
\end{aligned}
$$

and then yields

$$
A_{r}=\left|\frac{u+i L_{e 1}}{u+i}\right|
$$

$$
\varphi=-\arg \left(\frac{u+i L_{e 1}}{u+i}\right)
$$

Substituting equations (14f) and (14g) back into equation (11), the groundwater head in the confined aquifer can be written as

$$
H(z, t)=r_{\rho} A\left|\frac{u+i L_{e 1}}{u+i}\right| \cos \left[\omega t+\arg \left(\frac{u+i L_{e 1}}{u+i}\right)\right]
$$

which is essentially the same as the equation given by $\mathrm{Li}$ and Jiao [14] when the roof length $L \rightarrow \infty$ and $x \rightarrow-\infty$. Therefore, our analytical solution is a generalization of Li and Jiao's solution [14] when the roof length $L \rightarrow \infty$ and $x \rightarrow-\infty$.

For the semipermeable seabed, letting $L_{e}^{\prime} \rightarrow 0$ and $\theta \rightarrow 0$ in equations (12b) and (12d) yields

$$
\begin{aligned}
\lim _{\theta \rightarrow 0} A_{r} & =\left|\frac{p \tau+(1+i) a b\left[\left(L_{e 1}-1\right) z / b+\tau-L_{e 1}(1+i)\right] \tanh [(1+i) a b]}{p \tau+(1+i) a b \tanh [(1+i) a b]}\right| \\
\lim _{\theta \rightarrow 0} \varphi & =-\arg \left(\frac{p \tau+(1+i) a b\left[\left(L_{e 1}-1\right) z / b+\tau-L_{e 1}(1+\tau)\right] \tanh [(1+i) a b]}{p \tau+(1+i) a b \tanh [(1+i) a b]}\right) .
\end{aligned}
$$

Substituting equations (16a) and (16b) back into equation (11), the groundwater head in the semipermeable seabed can be obtained as follows:

$$
\begin{aligned}
H(z, t)= & r_{\rho} A\left|\frac{p \tau+(1+i) a b\left[\left(L_{e 1}-1\right) z / b+\tau-L_{e 1}(1+\tau)\right] \tanh [(1+i) a b]}{p \tau+(1+i) a b \tanh [(1+i) a b]}\right| \\
& \times \cos \left[\omega t+\arg \left(\frac{p \tau+(1+i) a b\left[\left(L_{e 1}-1\right) z / b+\tau-L_{e 1}(1+\tau)\right] \tanh [(1+i) a b]}{p \tau+(1+i) a b \tanh [(1+i) a b]}\right)\right] .
\end{aligned}
$$

3.2.2. Case 2: Impermeable Seabed $\left(K^{\prime} \rightarrow 0\right)$. When the semipermeable seabed becomes impermeable (i.e., $K^{\prime} \rightarrow 0$ ), in view of equation (9), one has $p \rightarrow 0$. Letting $p \rightarrow 0$ in equation (13a) yields

$$
\lim _{p \rightarrow 0} C=\frac{L_{e}-L_{e 1}+L_{e 1}-L_{e}}{\cosh [(1+\mathrm{i}) a b]}=0 .
$$

Letting $p \rightarrow 0$ in equations (12a) and (12c) yields

$$
\begin{aligned}
& \lim _{p \rightarrow 0} A_{r}=L_{e 1} \\
& \lim _{p \rightarrow 0} \varphi=0 .
\end{aligned}
$$

Substituting equations (18b) and (18c) back into equation (11), the groundwater head in the confined aquifer can be written as

$$
H(z, t)=r_{\rho} A L_{e 1} \cos (\omega t)
$$

The solution given by equation (19) is essentially the same as the solution of Van der Kamp [10] and Li et al. [17] when $K^{\prime} \rightarrow 0$ and $x \rightarrow-\infty$ except some notation differences.

3.3. The Amplitude Ratio $A_{r}$ and Phase Shift $\varphi$. The amplitude ratio $A_{r}$ and phase shift $\varphi$ of the groundwater head fluctuation in the confined aquifer and seabed are given by equations (12a), (12b), (12c), and (12d). Here, we will concentrate on the dependency of $A_{r}$ and $\varphi$ on the model 


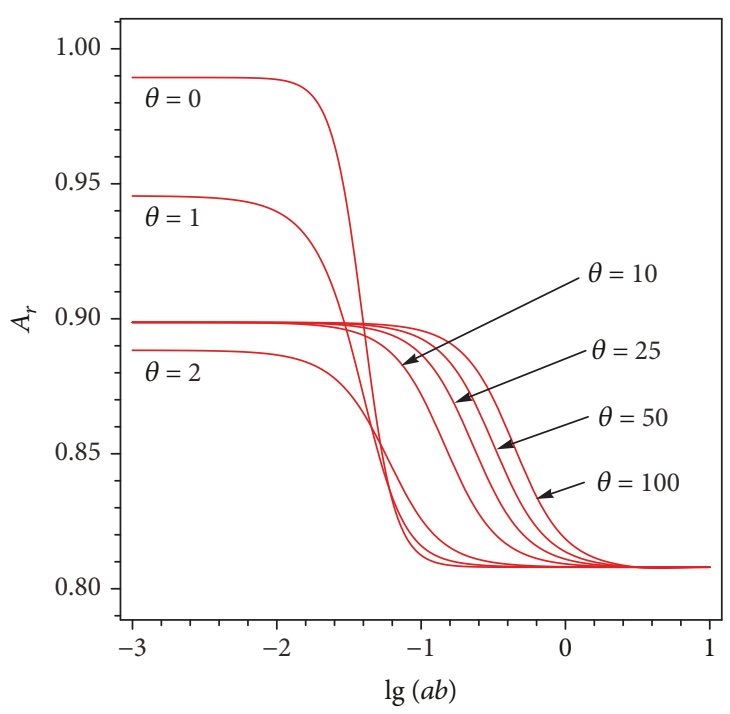

(a)

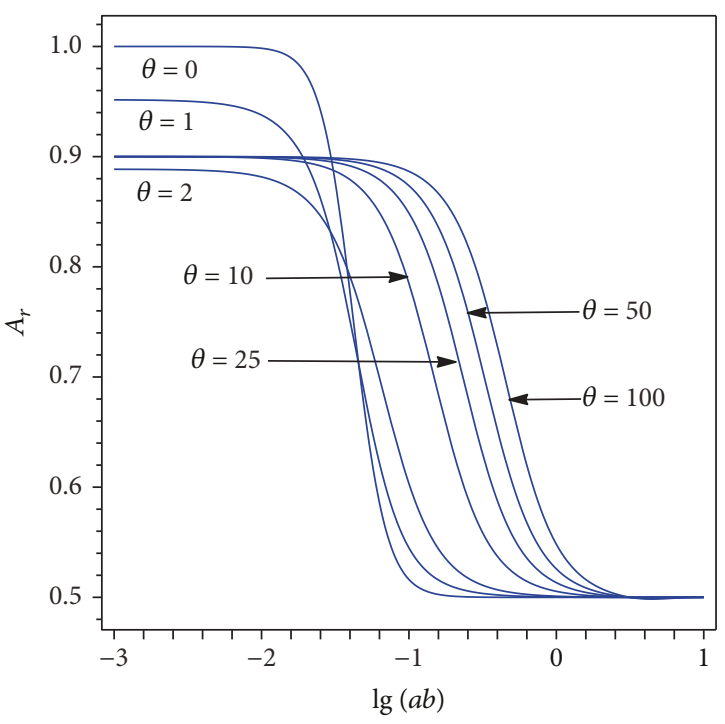

(b)

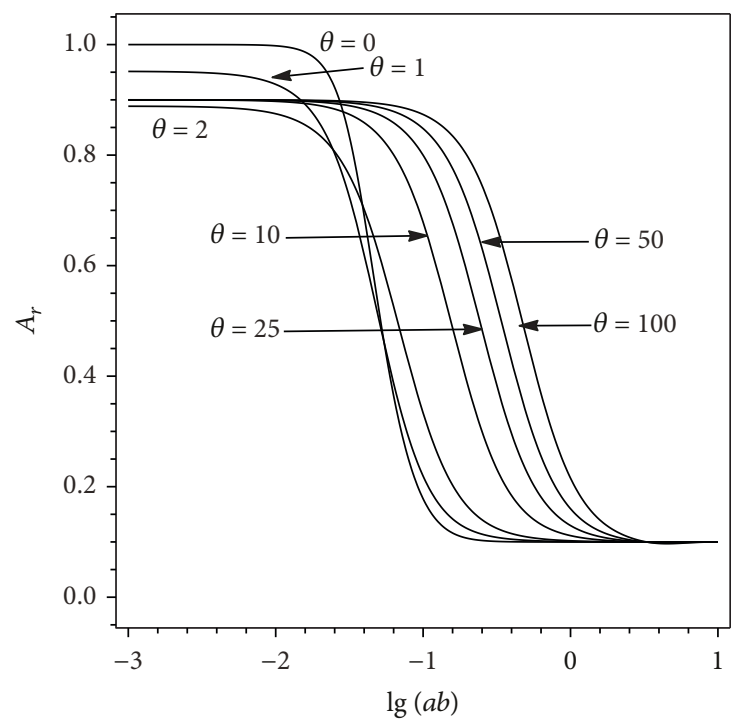

(c)

Figure 2: Changes of the amplitude ratio $A_{r}$ at the middle of the confined aquifer $z=0.5 b$ with $\lg (a b)$ for different values of $\theta$ when $L_{e 1}$ is equal to (a) 0.8 , (b) 0.5 , and (c) 0.1 . The loading coefficient $L_{e}^{\prime} \equiv 0.9$.

parameters such as the tidal loading effect of the confined aquifer $\left(L_{e 1}\right)$ and of the seabed $\left(L_{e}^{\prime}\right)$ and the dimensionless thickness $\theta$ of the semipermeable seabed and $a b$ of the confined aquifer. Since the amplitude ratio $A_{r}$ and the phase shift $\varphi$ depend on $z$, we discuss the changes of $A_{r}$ and $\varphi$ when $z$ is fixed at the middle of the confined aquifer $(z=0.5 b)$ and at the middle of the semipermeable seabed $\left(\mathrm{z}=b+0.5 b^{\prime}\right)$. The representative values of $p$ and $\tau$ in the literature are chosen for the following discussion: i.e., $1 \times 10^{-3}$ for $p$ and 3 for $\tau$ (see Table 1).

3.3.1. Changes of $A_{r}$ and $\varphi$ in the Confined Aquifer. Figure 2 shows how the amplitude ratio $A_{r}$ at the middle of the confined aquifer $z=0.5 b$ changes with $\lg (a b)$ for different values of $\theta$ and $L_{e 1}$ when $L_{e}^{\prime} \equiv 0.9$. From Figure 2, one can see that the amplitude ratio $A_{r}$ decreases from a constant close to 1 to $L_{e 1}$ (which equals $0.8,0.5$, and 0.1 , respectively) as $\lg (a b)$ increases from -3 to 1 . When $\lg (a b)$ is small $(\lg (a b) \leq-3)$, with the $\theta$ increasing, $A_{r}$ decreases from 1 firstly and then increases to 0.9 , which is the value of the tidal loading efficiency $\left(L_{e}^{\prime}\right)$ of the semipermeable seabed. When $\lg (a b) \rightarrow 1, A_{r}$ approaches the fixed values of $L_{e 1}$ and becomes independent of $\theta$. For intermediate values of $a b$ (approximately in the range $-2.5<\lg (a b)<1$ ), $A_{r}$ decreases significantly with $a b$. The curves for different $\theta$ values may cross each other near $\lg (a b)=-1.4$, indicating that $A_{r}$ is not always monotonic with respect to $\theta$. In addition, $A_{r}$ also increases with $L_{e 1}$ for fixed values of $a b$ and $\theta$. This can be observed when one compares the curves for the same values of $a b$ and $\theta$. 


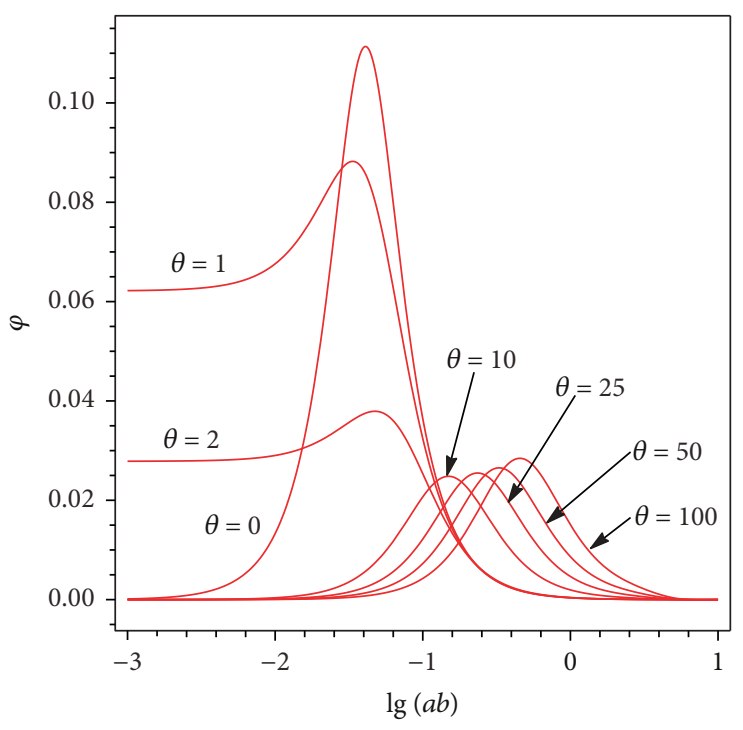

(a)

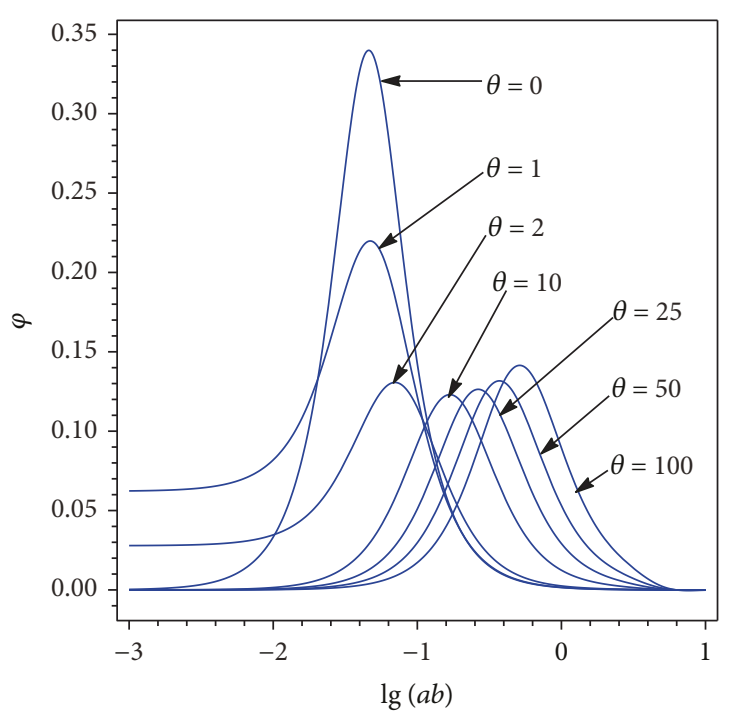

(b)

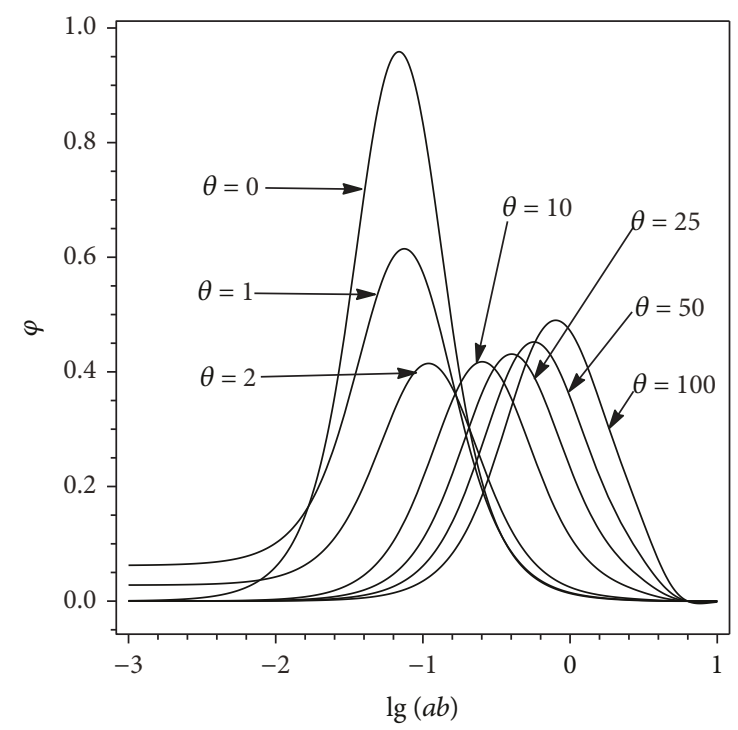

(c)

Figure 3: Changes of phase shift $\varphi$ at the middle of the confined aquifer $z=0.5 b$ with $\lg (a b)$ for different values of $\theta$ when $L_{e 1}$ is equal to (a) 0.8 , (b) 0.5 , and (c) 0.1 . The loading coefficient $L_{e}^{\prime} \equiv 0.9$.

Figure 3 shows how the phase shift $\varphi$ at the middle of the confined aquifer $z=0.5 b$ changes with $\lg (a b)$ for different values of $\theta$ and $L_{e 1}$ when $L_{e}^{\prime} \equiv 0.9$. From Figure 3, one can see that the value range of phase shift $\varphi$ decreases significantly with the tidal efficiency $L_{e 1}$. The value range of $\varphi$ is about $(0,0.96)$ for $L_{e 1}=0.1,(0,0.34)$ for $L_{e 1}=0.5$, and $(0$, $0.11)$ for $L_{e 1}=0.8$. When $a b$ is very small $(\lg (a b) \rightarrow-2.5)$, with the increasing of $\theta, \varphi$ increases from 0 firstly and then decreases to 0 . When $a b$ is very large $(\lg (a b) \rightarrow 1)$, the phase shift $\varphi$ tends to be zero for any values of $\theta$ and $L_{e 1}$. From Figure 3, one can also see that $\varphi$ is nonmonotonic with respect to $\theta$ and $a b$, which is due to the superposition of the multieffects such as the tidal loading, the downward propagation of the tidal signal, and the elastic storages of the semipermeable seabed and the aquifer. According to the curve when $\theta \rightarrow 0$ and $L_{e 1}=0.1$, the maximum phase shift is close to 1.0 (rad) which can lead to a time lag about $2 \mathrm{~h}$ for a semidiurnal tide and $4 \mathrm{~h}$ for a diurnal tide.

According to the discussions about the amplitude ratio $A_{r}$ and the phase shift $\varphi$ in the confined aquifer, one can conclude that tidal loading effects tend to enhance the amplitude and reduce the phase shift of the tidal groundwater head fluctuations in the confined aquifer. Figures 2 and 3 show that the increase of the dimensionless thickness of the upper semipermeable seabed may significantly enhance the tidal head fluctuation in the confined aquifer. Furthermore, Figures 2 and 3 demonstrate that an active range of $\lg (a b)$ $(-2.5 .0<\lg (a b)<1.0)$ exists in which both the amplitude and phase shift change with $a b$ significantly and both become insensitive to $\lg (a b)$ outside the range $(-2.5,1)$. 


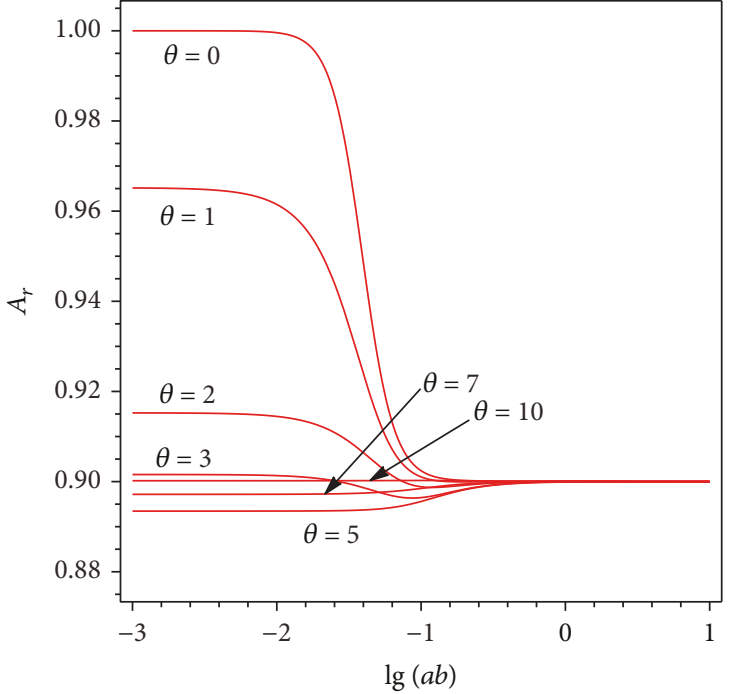

(a)

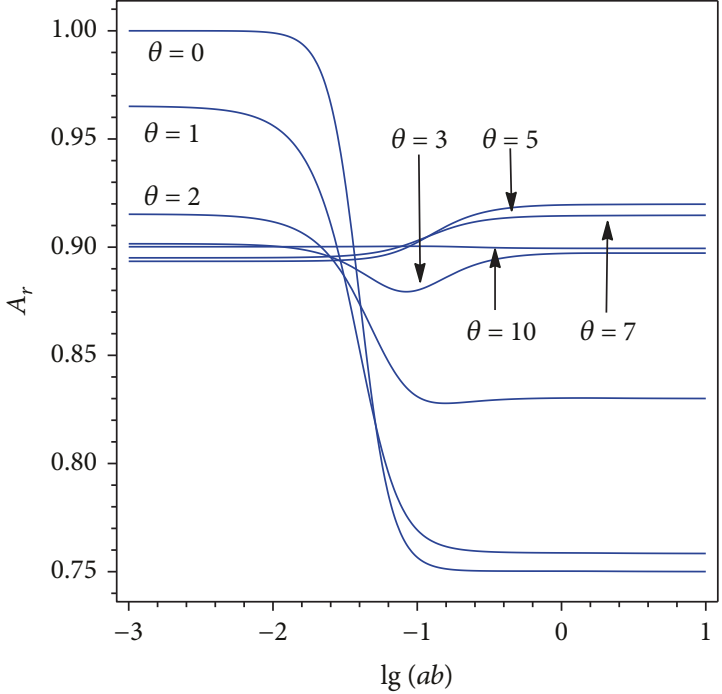

(b)

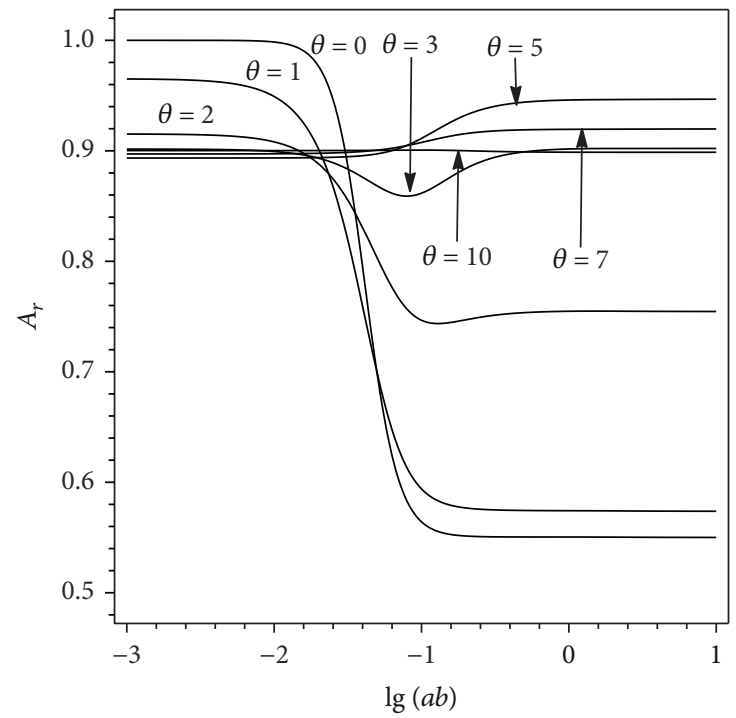

(c)

Figure 4: Changes of the amplitude ratio $A_{r}$ at the middle of the seabed semipermeable layer $z=b+0.5 b^{\prime}$ with $\lg (a b)$ for different values of $\theta$ when $L_{e 1}$ is equal to (a) 0.8 , (b) 0.5 , and (c) 0.1 . The loading coefficient $L_{e}^{\prime} \equiv 0.9$.

3.3.2. Changes of $A_{r}$ and $\varphi$ in the Seabed. Figure 4 shows how the amplitude ratio $A_{r}$ at the middle of the seabed semipermeable layer $z=b+0.5 b^{\prime}$ changes with $\lg (a b)$ for different values of $\theta$ and $L_{e 1}$ when $L_{e}^{\prime} \equiv 0.9$. It is obviously that no matter how the $\lg (a b)$ and $L_{e 1}$ change, the value of $A_{r}$ becomes constant when $\theta \geq 10$. However, the changes of $A_{r}$ become complex when $\theta<10$. When $a b$ is very small $(\lg (a b) \rightarrow-3)$, as $\theta$ is increasing from 0 to $10, A_{r}$ decreases from 1 firstly and then increases to 0.9 , which is the value of the tidal loading efficiency of the semipermeable seabed. As $\lg (a b)$ is increasing, the trends of $A_{r}$ are different with $\theta$ values. When $\theta$ is small $(\theta<5), A_{r}$ decreases firstly and then becomes a constant independent of $a b$. However, when $\theta$ is in the range $5 \leq \theta<10, A_{r}$ increases firstly and then becomes a constant independent of $a b$. When $\theta$ is around 3.0, $A_{r}$ decreases firstly and then increases with $a b$ and finally becomes a constant. The curves for different $\theta$ values cross each other near $\lg (a b)=-1.4$, indicating that the amplitude ratio $A_{r}$ of the seabed is not always monotonic with respect to $\theta$. Comparing Figures $4(\mathrm{a})-4(\mathrm{c})$, one can find that when $a b$ is larger, $A_{r}$ tends to be a constant value of 0.9 in Figure 4(a); however, $A_{r}$ tends to have different values shown in Figures 4(b) and 4(c). It may be caused due to the tidal loading effect in the confined aquifer.

Figure 5 shows how the phase shift $\varphi$ at the middle of the seabed semipermeable layer $z=b+0.5 b^{\prime}$ changes with $\lg (a b)$ for different values of $\theta$ and $L_{e 1}$ when $L_{e}^{\prime} \equiv 0.9$. The value range of $\varphi$ changes significantly with $L_{e 1}$, which is about $(0.00,0.05)$ for $L_{e 1}=0.8,(-0.11,0.14)$ for $L_{e 1}=0.5$, and $(-0.28,0.29)$ for $L_{e 1}=0.1$. Thus, the smaller the tidal efficiency $L_{e 1}$, the wider the value range of the phase shift. In general, the tidal loading effect tends to reduce the phase shift 


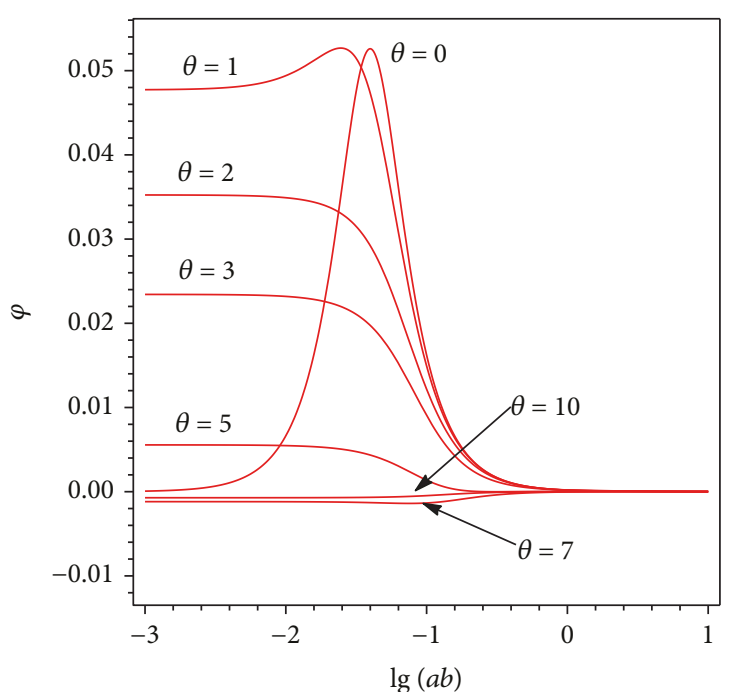

(a)

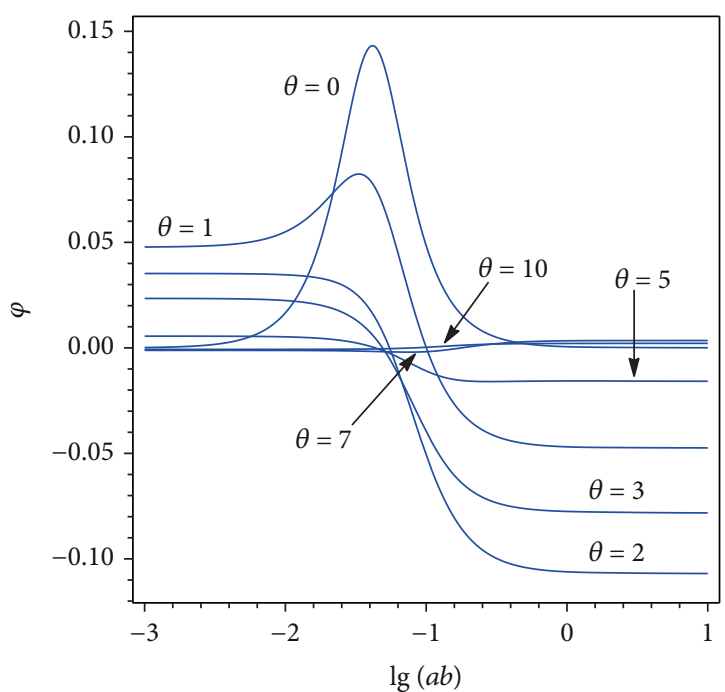

(b)

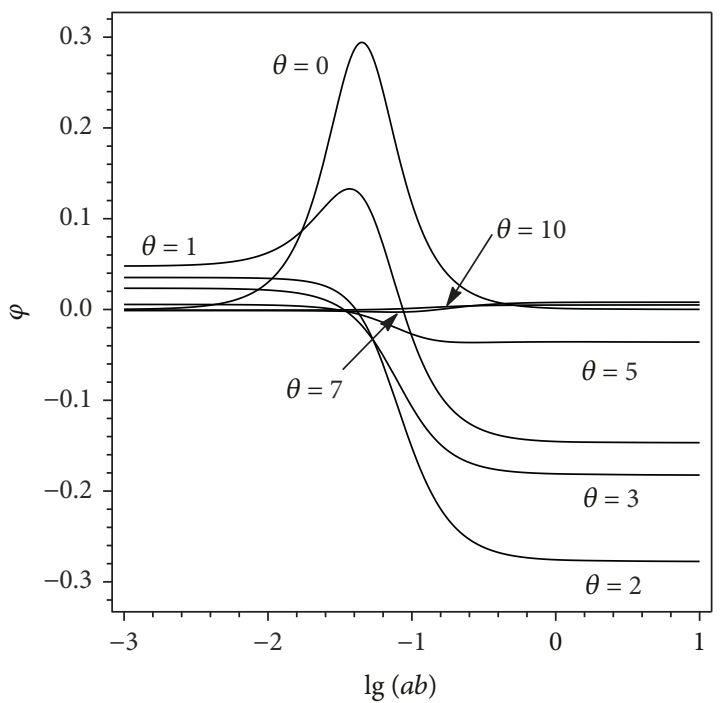

(c)

Figure 5: Changes of the phase shift $\varphi$ at the middle of the seabed semipermeable layer $z=b+0.5 b^{\prime}$ with $\lg (a b)$ for different values of $\theta$ when $L_{e 1}$ is equal to (a) 0.8 , (b) 0.5 , and (c) 0.1 . The loading coefficient $L_{e}^{\prime} \equiv 0.9$.

between the groundwater head and the tide fluctuations. No matter how $\lg (a b)$ and $L_{e 1}$ change, the value of $\varphi$ becomes constant when $\theta \geq 10$. When $\theta$ is equal to 0 or 1 , the phase shift $\varphi$ increases firstly and then decreases to a constant with the increasing of $\lg (a b)$. For $2 \leq \theta \leq 5$, the phase shift $\varphi$ decreases with $\lg (a b)$ monotonically to a constant. When $\theta$ is equal to or greater than 7 , the phase shift $\varphi$ increases with $L_{e 1}$ monotonically to a constant. Comparing Figures 5(a)5(c), one can also find that when $a b$ is larger, $\varphi$ tends to be a constant value of 0.9 in shown Figure 5(a); however, $\varphi$ tends to have different values shown in Figures 5(b) and 5(c). It may be also caused due to the tidal loading effect in the confined aquifer.

3.4. Effect of the Thickness Ratio $\tau$ and Hydraulic Conductivity Ratio p. Figure 6 shows how the amplitude ratio $A_{r}$ and phase shift $\varphi$ at the middle of the confined aquifer $z=0.5 b$ change with $\lg (a b)$ for different values of the thickness ratio $\tau$. The value range of $\tau$ used is from 1 to 10 , which is based on Table 2. Figure 6(a) demonstrates that when $\lg (a b)$ increases from -3 to 1 , the amplitude ratio $A_{r}$ decreases from $L_{e}^{\prime}$ to $L_{e 1}$ for any values of $\tau$. Given any values of $\lg (a b)$ in the range of $(-2,0.4)$, the amplitude ratio $A_{r}$ increases with $\tau$. Outside the range of $(-2,0.4)$, the amplitude ratio $A_{r}$ becomes insensitive to $\tau$. In Figure 6(b), the phase shift is a monopeak function of $\lg (a b)$ for any values of $\tau$. The increasing of the thickness ratio $\tau$ can decrease the phase shift when $-2.4<\lg (a b)<-1$ and increase the phase shift when $-0.4<\lg (a b)<0.6$. The impacts are complex in other ranges. Overall, the phase shift ranges from 0 to around 0.12 , a relatively narrow value range.

Figure 7 shows how the amplitude ratio $A_{r}$ and phase shift $\varphi$ at the middle of the semipermeable seabed layer $z=b+0.5 b^{\prime}$ change with $\lg (a b)$ for different values of $\tau$. 


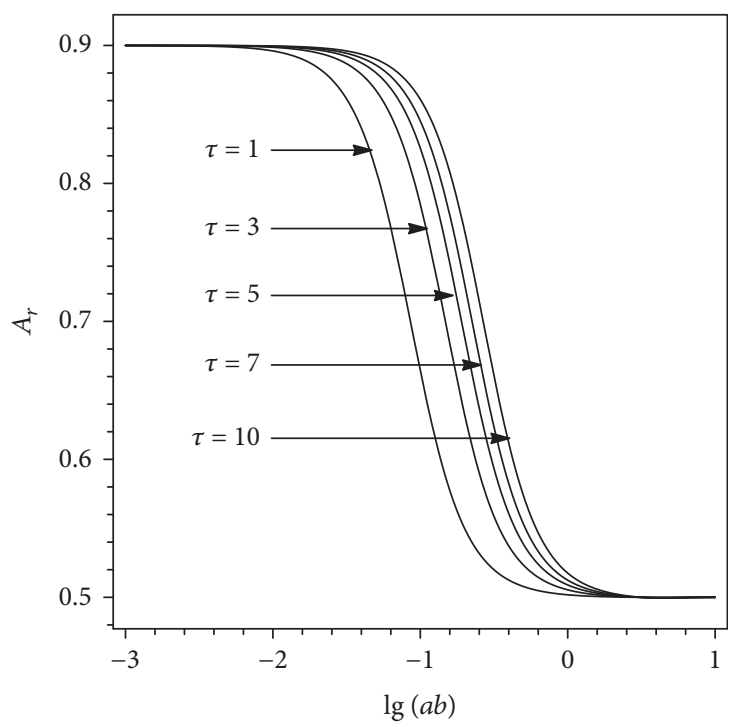

(a)

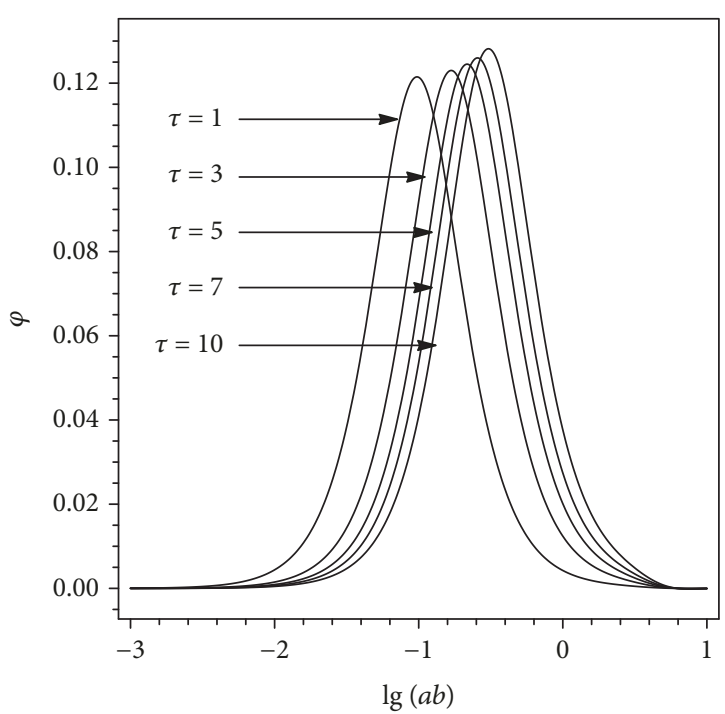

(b)

Figure 6: Changes of (a) amplitude ratio $A_{r}$ and (b) phase shift $\varphi$ at the middle of the confined aquifer $z=0.5 b$ with $\lg (a b)$ for different values of $\tau\left(\tau=b / b^{\prime}\right)$. The loading coefficients $L_{e 1}=0.5$ and $L_{e}^{\prime} \equiv 0.9$.

TABLE 2: Fixed parameters and their values used in the discussion.

\begin{tabular}{lccccc}
\hline Case no. & $z$ & $L_{e 1}$ & $\theta$ & $T$ & $p$ \\
\hline 1 & $0.5 b$ & 0.5 & 10 & $1 \sim 10$ & $10^{-3}$ \\
& $b+0.5 b^{\prime}$ & 0.5 & 2 & $1 \sim 10$ & $10^{-3}$ \\
2 & $0.5 b$ & 0.5 & 10 & 3 & $10^{-6} \sim 10^{-1}$ \\
& $b+0.5 b^{\prime}$ & 0.5 & 2 & 3 & $10^{-6} \sim 10^{-1}$ \\
\hline
\end{tabular}

The parameters in Case 1 are used to discuss the effect of the thickness ratio $\tau$ $\left(\tau=b / b^{\prime}\right)$. The parameters in Case 2 are used to discuss the effect of hydraulic conductivity ratio $p\left(p=K^{\prime} / K_{1}\right)$.

Figure 7(a) shows that the amplitude ratio decreases with $\lg (a b)$ first and then tends to be a constant with a slight oscillations. The increasing of the thickness ratio $\tau$ can lead to the increase of the amplitude for any value of $\lg (a b)$ in the range $-2.4<\lg (a b)<0$. Figure 7 (b) shows that the phase shift decreases with $\lg (a b)$ monotonically from about 0.035 to about -0.11 , a very narrow value range. The increasing of the thickness ratio $\tau$ can lead to the increase of the phase shift for any value of $\lg (a b)$ in the range $-2<\lg (a b)<0.4$.

Figure 8 shows how the changes of the amplitude ratio $A_{r}$ and phase shift $\varphi$ at the middle of the confined aquifer $z=$ $0.5 b$ with $\lg (a b)$ for different values of the hydraulic conductivity ratio $p$, which ranges from $10^{-5}$ to $10^{-2}$ according to Table 1. Figure 8(a) shows that the amplitude ratio decreases with $\lg (a b)$ monotonically from $0.9\left(L_{e}^{\prime}\right)$ to $0.5\left(L_{e 1}\right)$ for any fixed value of $p$. The increasing of $p$ can lead to the increase of the amplitude ratio for any value of $\lg (a b)$ in the range $-2.8<\lg (a b)<0.4$. Figure 8 (b) shows that the phase shift is a monopeak function of $\lg (a b)$ for any given value of $p$. The values of $\lg (a b)$ where the curve peaks increase with $p$. The value range of the phase shift is from 0 to less than 0.15 .

Figure 9 shows how the amplitude ratio $A_{r}$ and phase shift $\varphi$ at the middle of the semipermeable seabed layer $z=$ $b+0.5 b^{\prime}$ change with $\lg (a b)$ for different values of $p$. Figure 9(a) shows that the amplitude ratio decreases with lg $(a b)$ first and then tends to be a constant with slight oscillations. The increasing of hydraulic conductivity ratio $p$ can lead to the increase of the amplitude for any value of $\lg (a b)$ in the range $-3<\lg (a b)<-0.6$. Figure 9 (b) shows that the phase shift decreases with $\lg (a b)$ monotonically from about 0.035 to about -0.11 , a very narrow value range. The increasing of hydraulic conductivity ratio $p$ can lead to the increase of the phase shift for any value of $\lg (a b)$ in the range $-3<$ $\lg (a b)<1$.

3.5. Groundwater Head at Different Depths of the Confined Aquifer. In order to investigate the differences of groundwater head fluctuations at different depths of the confined aquifer, we considered the changes of $A_{r}$ and $\varphi$ at the top and the bottom of the confined aquifer. The parameters $p$ and $\tau$ are fixed in the following discussion: $p=1 \times 10^{-3}$ for $\tau=3$. Figure 10 shows how the amplitude ratio $A_{r}$ at the top and bottom of the confined aquifer changes with $\lg (a b)$ for different values of $\theta$ and $L_{e 1}$ when $L_{e}^{\prime} \equiv 0$.9. The variation patterns of $A_{r}$ at the top and bottom of the aquifer are similar to that at the middle of the confined aquifer (Figure 2). When $\theta=1$, Figure 10(a) shows that the curves of $A_{r}$ at the top and bottom of the aquifer coincide completely with each other, and so do the curves for the phase shift $\varphi$ in Figure 10(b). Figures $10(\mathrm{c})$ and $10(\mathrm{e})$ show that when $\lg (a b) \leq-0.4$, the curves of $A_{r}$ at the top and bottom of the aquifer are also entirely coincident; however, $A_{r}$ at the top of the aquifer becomes larger than that at the bottom of the aquifer with $\theta$ when $\lg (a b)>-0.4$. The difference in the value of $A_{r}$ between the top and bottom of the aquifer decreases gradually as $L_{e 1}$ increases. Figures 10(d) and 10(f) show that the phase shift $\varphi$ at the top of the aquifer becomes smaller than that at the bottom of the aquifer for large values of $\theta$ 


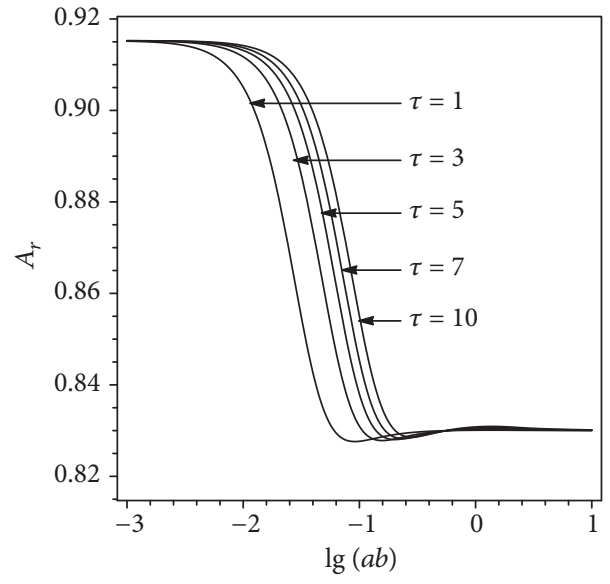

(a)

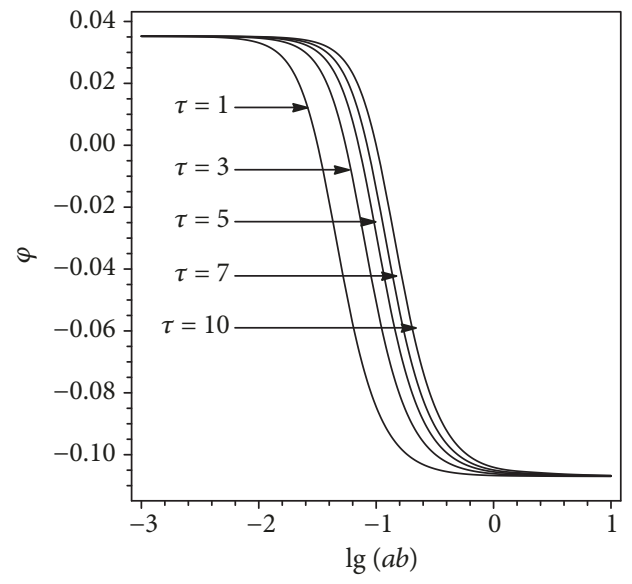

(b)

Figure 7: Changes of (a) amplitude ratio $A_{r}$ and (b) phase shift $\varphi$ at the middle of the semipermeable seabed layer $z=b+0.5 b^{\prime}$ with lg $(a b)$ for different values of $\tau\left(\tau=b / b^{\prime}\right)$. The loading coefficients $L_{e i}=0.5$ and $L_{e}^{\prime} \equiv 0.9$.

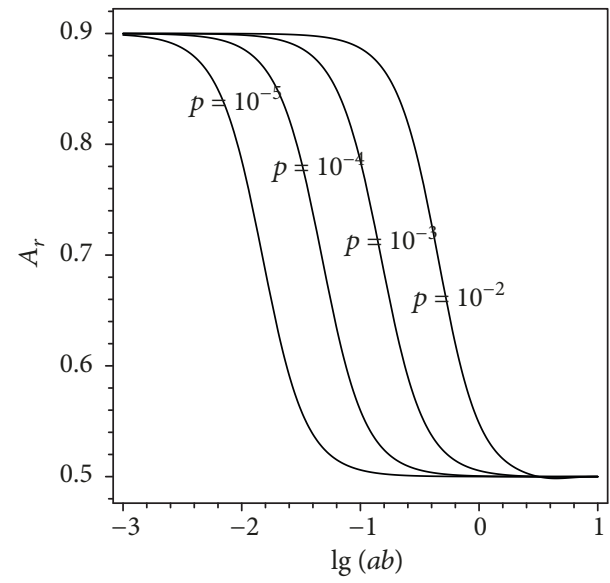

(a)

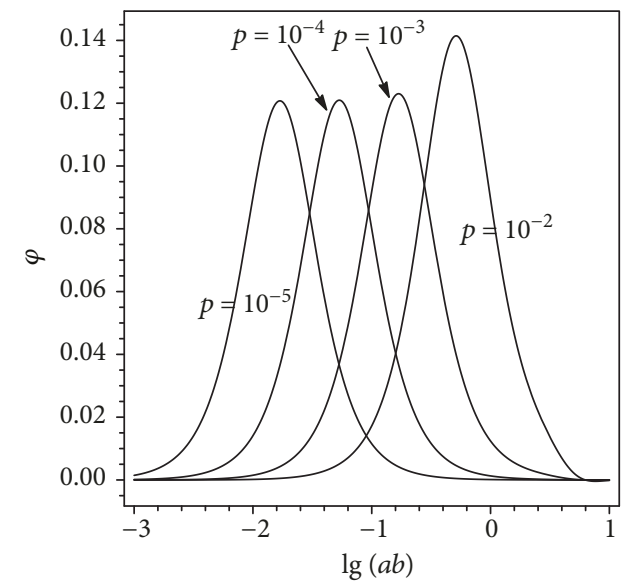

(b)

FIGURE 8: Changes of (a) amplitude ratio $A_{r}$ and (b) phase shift $\varphi$ at the middle of the confined aquifer $z=0.5 b$ with lg $(a b)$ for different values of $p\left(p=K^{\prime} / K_{1}\right)$. The loading coefficients $L_{e 1}=0.5$ and $L_{e}^{\prime} \equiv 0.9$.

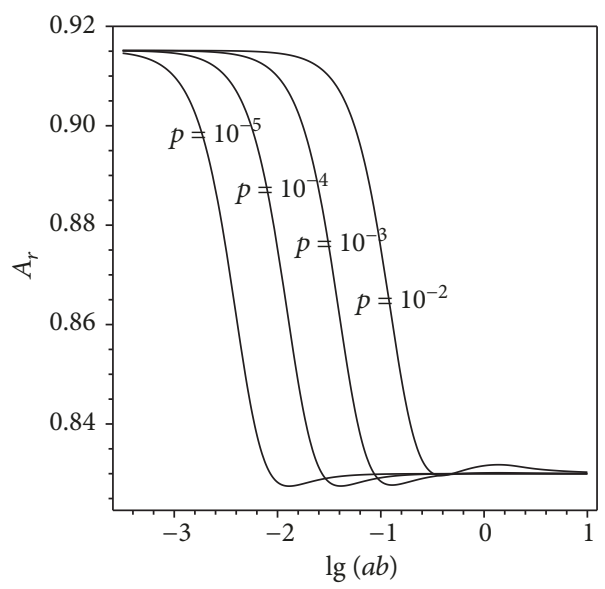

(a)

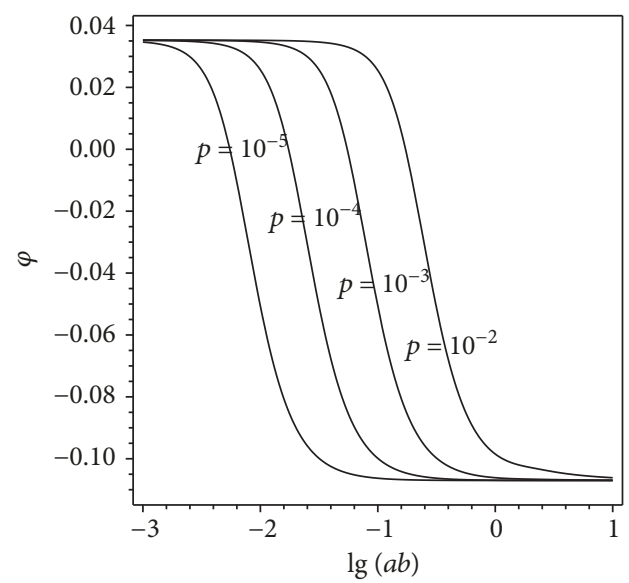

(b)

FIgURE 9: Changes of (a) amplitude ratio $A_{r}$ and (b) phase shift $\varphi$ at the middle of the seabed semipermeable layer $z=b+0.5 b^{\prime}$ with lg $(a b)$ for different values of $p\left(p=K^{\prime} / K_{1}\right)$. The loading coefficients $L_{e 1}=0.5$ and $L_{e}^{\prime} \equiv 0.9$. 


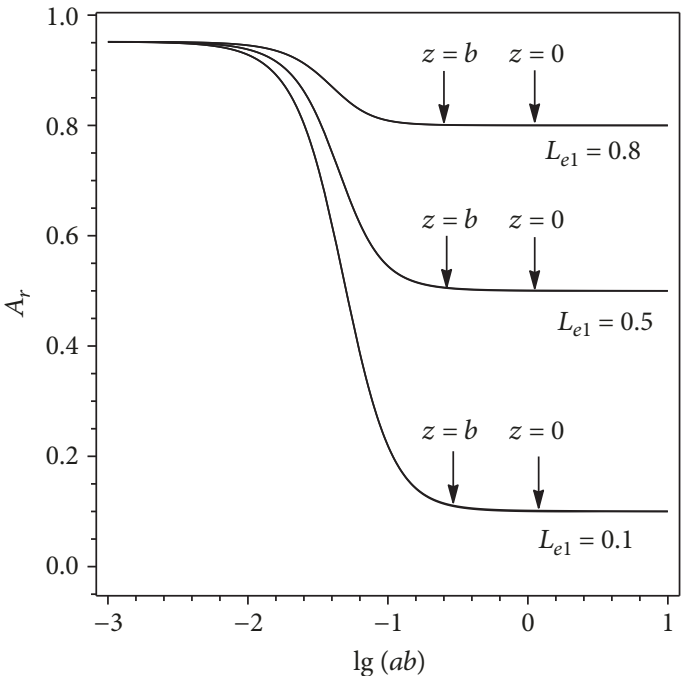

(a)

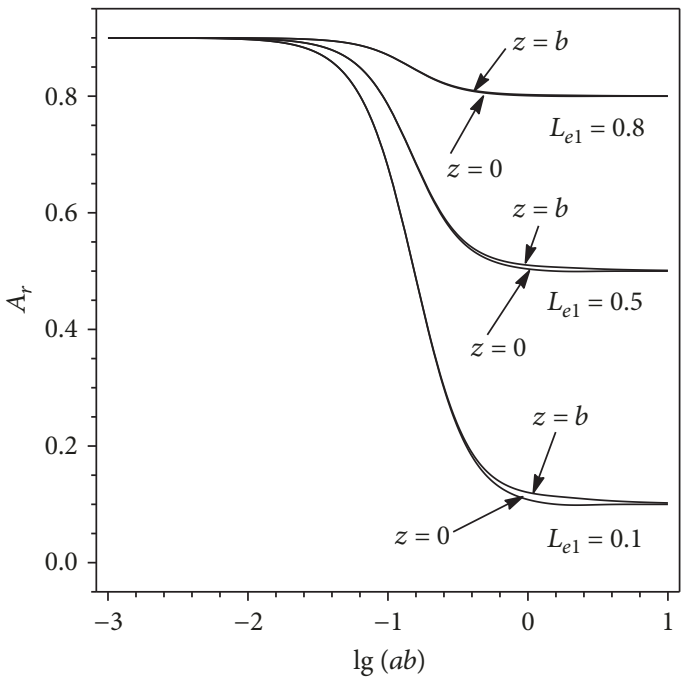

(c)

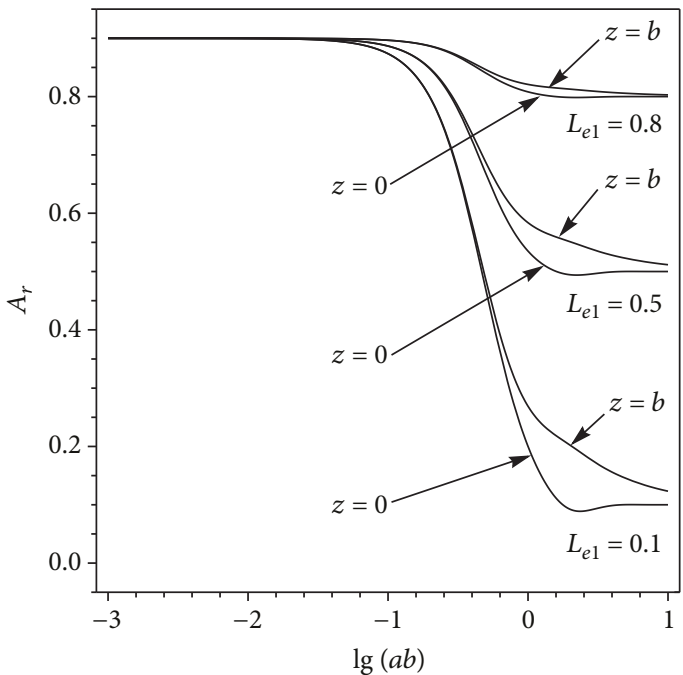

(e)

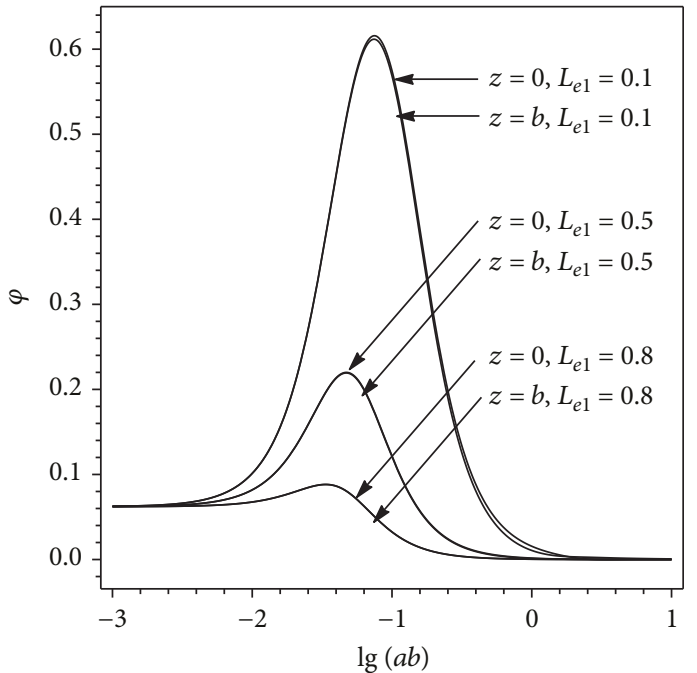

(b)

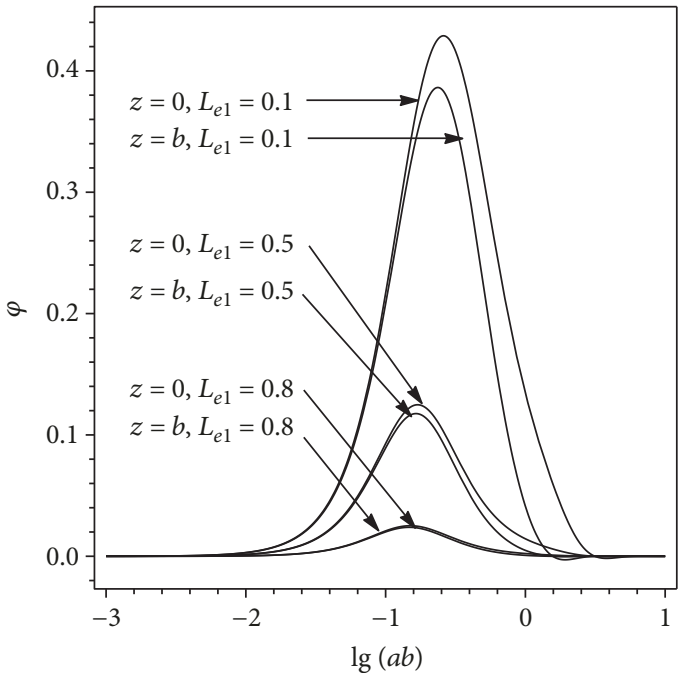

(d)

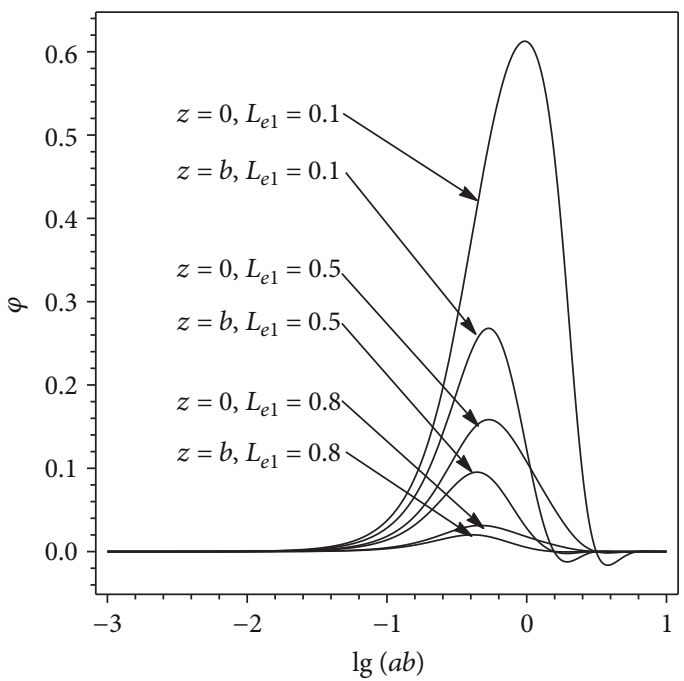

(f)

Figure 10: Changes of amplitude ratio $A_{r}$ and phase shift $\varphi$ at the top $z=b$ and bottom $z=0$ of the confined aquifer with lg $(a b)$ for different values of $\theta$ and $L_{e 1}$ when $L_{e}^{\prime} \equiv 0.9$. (a, b) $A_{r}$ and $\varphi$ for $\theta=1$; (c, d) $A_{r}$ and $\varphi$ for $\theta=10$; and (e, f) $A_{r}$ and $\varphi$ for $\theta=100$. 
(10 and 100). The difference in the value of $\varphi$ between the bottom and top of the aquifer decreases gradually as $L_{e 1}$ increases. It can be concluded that the discrepancy between the tidal groundwater fluctuations at the top and bottom of the confined aquifer becomes larger with the increasing of $\theta$ and the decreasing of $L_{e 1}$.

\section{Conclusion}

This paper investigated the tidal groundwater head fluctuation in a submarine confined leaky aquifer system. A vertical one-dimensional mathematical model is given with the analytical solution derived. Both the leakage and elastic storage of the semipermeable seabed are considered in this model. The derived analytical solution is different from previous analytical solutions by Li and Jiao [14] and Guarracino et al. [18] which focus on the analysis in the inland portion. Although Li et al. [17] give the analytical solutions in the offshore part, they did not do sensitivity analysis of parameters of the aquifers in the offshore part to head fluctuations of the aquifers there. Our solution quantifies the tidal groundwater head fluctuations in an offshore submarine aquifer system, which contains a confined aquifer and a semipermeable seabed.

The effects of several dimensionless model parameters, including the tidal loading efficiencies $\left(L_{e 1}\right.$ and $\left.L_{e}^{\prime}\right)$ of the confined aquifer and the semipermeable seabed, the dimensionless thickness $a b$ of the confined aquifer, and the dimensionless thickness $\theta$ of the seabed, on the tidal groundwater fluctuations are quantitatively discussed and analyzed. The following conclusions can be drawn based on the solution analyses and discussion: (1) The tidal loading effect tends to enhance the amplitude of the tidal groundwater fluctuation in the confined aquifer system, and it can also tend to reduce the phase difference between the fluctuation of the groundwater head in the aquifer (or an aquitard) and the tidal fluctuations. (2) The increase of the thickness ratio or the hydraulic conductivity ratio can not only result in a larger amplitude in the confined aquifer but also lead to a larger phase shift. (3) The discrepancy between the tidal groundwater fluctuations at the top and bottom of the confined aquifer increases when $\theta$ increases and/or $L_{e 1}$ decreases.

\section{Appendix}

\section{A. Derivation of Solutions (10a) and (10b)}

Let $F(z, t)$ be a complex function of the real variables $z$ and $t$ that satisfies equations (1), (2), (3), (4), and (5) after $h_{S}(t)=r_{\rho} A \cos (\omega t)$ in equations (1) and (2) is replaced by $r_{\rho} A \exp (i \omega t)$, where $i=\sqrt{-1}$.

Let $H(z, t)$ be the solution to (1), (2), (3), (4), and (5); it follows that

$$
H(z, t)=\operatorname{Re}(F(z, t))
$$

where Re denotes the real part of the followed complex expression. Now suppose

$$
F(z, t)=r_{\rho} A Z(z) \exp (\boldsymbol{i} \omega \boldsymbol{t})
$$

where $Z(z)$ is an unknown function of $z$. Substituting (A.2) into the five equations which $F(z, t)$ satisfies and extending the five resultant real equations into complex ones with respect to the unknown complex function $Z(z)$, then dividing the results by $r_{\rho} A \exp (\boldsymbol{i} \omega \boldsymbol{t})$, yield

$$
\begin{aligned}
K_{1} Z^{\prime \prime}-i \omega S_{S 1} Z+i \omega S_{S 1} L_{e 1} & =0, \quad 0<z<b, \\
K Z^{\prime \prime}-i \omega S_{S}^{\prime} Z+i \omega S_{S}^{\prime} L_{e}^{\prime} & =0, \quad b<z<b+b^{\prime}, \\
Z\left(b+b^{\prime}\right) & =1, \\
\lim _{z \downarrow b} Z(z) & =\lim _{z \uparrow b} Z(z), \\
K^{\prime} \lim _{z \downarrow b} Z^{\prime}(z) & =K_{1} \lim _{z \uparrow b} Z^{\prime}(z), \\
Z^{\prime}(0) & =0 .
\end{aligned}
$$

The solution to (A.3), (A.4), (A.5), (A.6), (A.7), and (A.8) is

$$
Z(z)=\left\{\begin{array}{l}
C \cosh [(1+i) a z]+L_{e 1}, \quad 0<z<b, \\
C_{1} e^{((1+\mathrm{i}) \theta z) / b^{\prime}}+C_{2} e^{-((1+i) \theta z) / b^{\prime}}+L_{e}^{\prime}, \quad b<z<b+b^{\prime},
\end{array}\right.
$$

where $a$ and $\theta$ are the dimensionless model parameters given by equations (6) and (7), respectively, and $C, C_{1}$, and $C_{2}$ are the complex constants given by equations (13a), (13b), (13c), (13d), (13e), and (13f).

\section{B. Derivation of Solution (11)}

The following is the derivation deformation of the analytical solutions (10a) and (10b).

$$
\begin{aligned}
H(z, t) & =\operatorname{Re}\left[r_{\rho} A Z(z) \exp (\boldsymbol{i} \omega \boldsymbol{t})\right] \\
& =r_{\rho} A \operatorname{Re}[|Z| \exp (i \arg Z) \cdot \exp (i \omega t)] \\
& =r_{\rho} A \operatorname{Re}[|Z| \exp [i(\arg Z+\omega t)] \\
& =r_{\rho} A \operatorname{Re}\{|Z|[\cos (\arg Z+\omega t)+i \sin (\arg Z+\omega t)]\} \\
& =r_{\rho} A|Z| \cos (\omega t-(-\arg Z))
\end{aligned}
$$

\section{Derivation of Solutions (13a), (13c), and (13d)}

Putting equation (A.9) into equation (A.6) yields

$$
C \cosh [(1+\mathrm{i}) a b]+L_{e 1}=C_{1} e^{(1+\mathrm{i}) \theta \tau}+C_{2} e^{-(1+\mathrm{i}) \theta \tau}+L_{e}^{\prime},
$$


and then, the following equation can be obtained from (C.1):

$$
C=\frac{C_{1} \exp [(1+i) \tau \theta]+C_{2} \exp [-(1+i) \tau \theta]+L_{e}^{\prime}-L_{e 1}}{\cosh [(1+i) a b]}
$$

Getting the derivative of equation (A.9) and then putting them into equation (A.6) yield

$$
C \cosh [(1+\mathrm{i}) a b]=\frac{\theta p \tau}{a b}\left[C_{1} e^{(1+\mathrm{i}) \theta \tau}-C_{2} e^{-(1+\mathrm{i}) \theta \tau}\right] .
$$

Putting equation (A.9) into equation (A.5) yields

$$
C_{1} e^{(1+\mathrm{i}) \theta} e^{(1+\mathrm{i}) \theta \tau}+C_{2} e^{-(1+\mathrm{i}) \theta} e^{-(1+\mathrm{i}) \theta \tau}=1-L_{e}^{\prime}
$$

The solutions to (C.2), (C.3), and (C.4) are

$$
\begin{aligned}
C_{1}= & \frac{1}{\Delta}\left\{e ^ { - ( 1 + \mathrm { i } ) \tau \theta } \left[\tanh [(1+i) a b]\left(L_{e}^{\prime}-L_{e 1}\right) e^{-(1+\mathrm{i}) \theta}\right.\right. \\
& \left.\left.+\left(\frac{\theta p \tau}{a b}+\tanh [(1+i) a b]\right)\left(1-L_{e}^{\prime}\right)\right]\right\}, \\
C_{2}= & \frac{1}{\Delta}\left\{e ^ { ( 1 + i ) \tau \theta } \left[-\tanh [(1+i) a b]\left(L_{e}^{\prime}-L_{e 1}\right) e^{(1+\mathrm{i}) \theta}\right.\right. \\
& \left.\left.+\left(\frac{\theta p \tau}{a b}+\tanh [(1+i) a b]\right)\left(1-L_{e}^{\prime}\right)\right]\right\},
\end{aligned}
$$

with

$$
\begin{aligned}
\Delta & =\frac{2 \theta p \tau}{a b} \cosh [(1+i) \theta]+2 \tanh [(1+i) a b] \sinh [(1+i) \theta], \\
p & =\frac{K^{\prime}}{K_{1}} \\
\tau & =\frac{b}{b^{\prime}} .
\end{aligned}
$$

\section{Data Availability}

The data used to support the findings of this study are included within the article.

\section{Disclosure}

This article was modified based on the master thesis of Mr. Zongzhong Song.

\section{Conflicts of Interest}

The authors declare that they have no conflicts of interest.

\section{Acknowledgments}

This work was supported by the Key Program of the National Natural Science Foundation of China (Grant No. 41430641) and the National Basic Research Program of China ("973" Program, Grant No. 2015CB452902). This work was also sponsored by Guangdong Provincial Key Laboratory of Soil and Groundwater Pollution Control (No. 2017B030301012) and State Environmental Protection Key Laboratory of Integrated Surface Water-Groundwater Pollution Control.

\section{References}

[1] C. E. Jacob, "Flow of groundwater," in Engineering Hydraulics, H. Rouse, Ed., pp. 321-386, John Wiley, New York, NY, USA, 1950.

[2] J. G. Ferris, Cyclic Fluctuations of Water Level as a Basis for Determining Aquifer Transmissibility, IASH Publ, 1951.

[3] P. Banerjee, D. Sarwade, and V. S. Singh, "Characterization of an island aquifer from tidal response," Environmental Geology, vol. 55, no. 4, pp. 901-906, 2008.

[4] P. A. Carr and G. S. van der Kamp, "Determining aquifer characteristics by the tidal method," Water Resources Research, vol. 5, no. 5, pp. 1023-1031, 1969.

[5] E. S. Carol, E. E. Kruse, J. L. Pousa, and A. R. Roig, "Determination of heterogeneities in the hydraulic properties of a phreatic aquifer from tidal level fluctuations: a case in Argentina," Hydrogeology Journal, vol. 17, no. 7, pp. 1727-1732, 2009.

[6] C. Drogue, M. Razack, and P. Krivic, "Survey of a coastal karstic aquifer by analysis of the effect of the sea-tide: example of the Kras of Slovenia, Yugoslavia," Environmental Geology and Water Sciences, vol. 6, no. 2, pp. 103-109, 1984.

[7] A. D. Erskine, "The effect of tidal fluctuation on a coastal aquifer in the UK," Ground Water, vol. 29, no. 4, pp. 556-562, 1991.

[8] A. Pandit, C. C. EI-Khazen, and S. P. Sivaramapillai, "Estimation of hydraulic conductivity values in a coastal aquifer," Ground Water, vol. 29, no. 2, pp. 175-180, 1991.

[9] M. E. Series, "Determining the mean hydraulic gradient of ground water affected by tidal fluctuations," Ground Water, vol. 29, no. 4, pp. 549-555, 1991.

[10] G. Van der Kamp, "Tidal fluctuations in a confined aquifer extending under the sea," in 24th Proceedings of the International Geological Congress, pp. 101-106, Montreal, Canada, 1972.

[11] G. M. Li and C. X. Chen, "Determining the length of confined aquifer roof extending under the sea by the tidal method," Journal of Hydrology, vol. 123, pp. 97-104, 1991.

[12] J. J. Jiao and Z. H. Tang, "An analytical solution of groundwater response to tidal fluctuation in a leaky confined aquifer," Water Resources Research, vol. 35, no. 3, pp. 747-751, 1999.

[13] H. L. Li and J. J. Jiao, "Analytical studies of groundwater-head fluctuation in a coastal confined aquifer overlain by a semipermeable layer with storage," Advances in Water Resources, vol. 24, no. 5, pp. 565-573, 2001.

[14] H. L. Li and J. J. Jiao, "Tide-induced groundwater fluctuation in a coastal leaky confined aquifer system extending under the sea," Water Resources Research, vol. 37, no. 5, pp. 11651171, 2001.

[15] D. S. Jeng, L. Li, and D. A. Barry, “Analytical solution for tidal propagation in a coupled semi-confined/phreatic coastal 
aquifer," Advances in Water Resources, vol. 25, no. 5, pp. 577$584,2002$.

[16] H. L. Li and J. J. Jiao, "Analytical solutions of tidal groundwater flow in coastal two-aquifer system," Advances in Water Resources, vol. 25, no. 4, pp. 417-426, 2002.

[17] G. H. Li, H. L. Li, and M. C. Boufadel, "The enhancing effect of the elastic storage of the seabed aquitard on the tide-induced groundwater head fluctuation in confined submarine aquifer systems," Journal of Hydrology, vol. 350, no. 1-2, pp. 83-92, 2008.

[18] L. Guarracino, J. Carrera, and E. Vázquez-Sune, “Analytical study of hydraulic and mechanical effects on tide-induced head fluctuation in a coastal aquifer system that extends under the sea," Journal of Hydrology, vol. 450-451, pp. 150-158, 2012.

[19] X. J. Wang, H. L. Li, L. Wan, F. T. Liu, and X. W. Jiang, "Loading effect of water table variation and density effect on tidal head fluctuations in a coastal aquifer system," Water Resources Research, vol. 48, no. 9, article W09501, 2012.

[20] C. Y. Wang, H. L. Li, L. Wan, X. J. Wang, and X. W. Jiang, "Closed-form analytical solutions incorporating pumping and tidal effects in various coastal aquifer systems," Advances in Water Resources, vol. 69, pp. 1-12, 2014.

[21] J. Y. Gao, X. J. Wang, Y. Zhang, and H. L. Li, "Estimating submarine groundwater discharge and associated nutrient inputs into Daya Bay during spring using radium isotopes," Water Science and Engineering, vol. 11, no. 2, pp. 120-130, 2018.

[22] J. J. Jiao, L. Shi, X. Kuang, C. M. Lee, W. W. S. Yim, and S. Yang, "Reconstructed chloride concentration profiles below the seabed in Hong Kong (China) and their implications for offshore groundwater resources," Hydrogeology Journal, vol. 23, no. 2, pp. 277-286, 2015.

[23] A. C. Knight, A. D. Werner, and L. K. Morgan, "The onshore influence of offshore fresh groundwater," Journal of Hydrology, vol. 561, pp. 724-736, 2018

[24] V. E. A. Post, J. Groen, H. Kooi, M. Person, S. Ge, and W. M. Edmunds, "Offshore fresh groundwater reserves as a global phenomenon," Nature, vol. 504, no. 7478, pp. 71-78, 2013.

[25] S. C. Solórzano-Rivas and A. D. Werner, "On the representation of subsea aquitards in models of offshore fresh groundwater," Advances in Water Resources, vol. 112, pp. 283-294, 2018.

[26] X. Yu and H. A. Michael, "Offshore pumping impacts onshore groundwater resources and land subsidence," Geophysical Research Letters, vol. 46, no. 5, pp. 2553-2562, 2019.

[27] M.-H. Chuang and H.-D. Yeh, "An analytical solution for the head distribution in a tidal leaky confined aquifer extending an infinite distance under the sea," Advances in Water Resources, vol. 30, no. 3, pp. 439-445, 2007.

[28] M. S. Hantush and C. E. Jacob, "Non-steady radial flow in an infinite leaky aquifer," Transactions, American Geophysical Union, vol. 36, no. 1, pp. 95-100, 1955.

[29] D. O. Gregg, "An analysis of ground-water fluctuations caused by ocean tides in Glynn County, Georgia," Ground Water, vol. 4, no. 3, pp. 24-32, 1966.

[30] M. L. Merritt, Estimating Hydraulic Properties of the Floridan Aquifer System by Analysis of Earth-Tide, Ocean-Tide, and Barometric Effects, Collier and Hendry Counties, Florida, U.S Geological Survey: Water-Resources Investigations Report 2003-4267, 2004.

[31] N. T. Sheahan, "Injection/extraction well system-a unique seawater intrusion barrier," Ground Water, vol. 15, no. 1, pp. 32-50, 1977.
[32] V. Batu, Aquifer Hydraulics: A Comprehensive Guide to Hydrogeologic Data Analysis, Wiley, New York, NY, USA, 1998.

[33] S. P. Neuman and P. A. Witherspoon, "Field determination of the hydraulic properties of leaky multiple aquifer systems," Water Resources Research, vol. 8, no. 5, pp. 1284-1298, 1972.

[34] K. J. Dawson and J. D. Istok, Aquifer Testing: Design and Analysis of Pumping and Slug Tests, Lewis Publishers, Boca Raton, FL, USA, 1991.

[35] C. X. Chen and J. J. Jiao, "Numerical simulation of pumping tests in multilayer wells with non-Darcian flow in the wellbore," Ground Water, vol. 37, no. 3, pp. 465-474, 1999. 

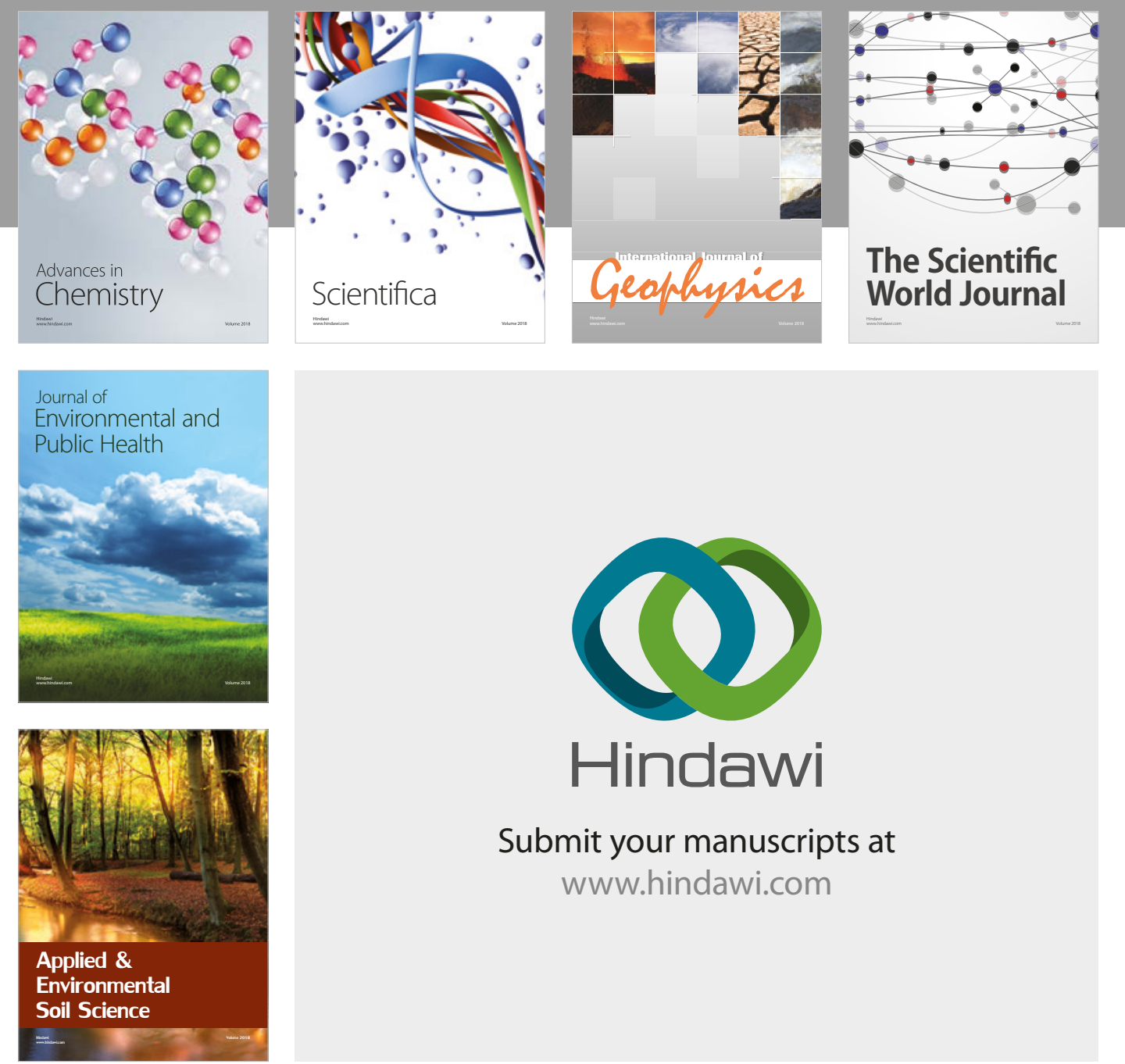

The Scientific

\section{World Journal}
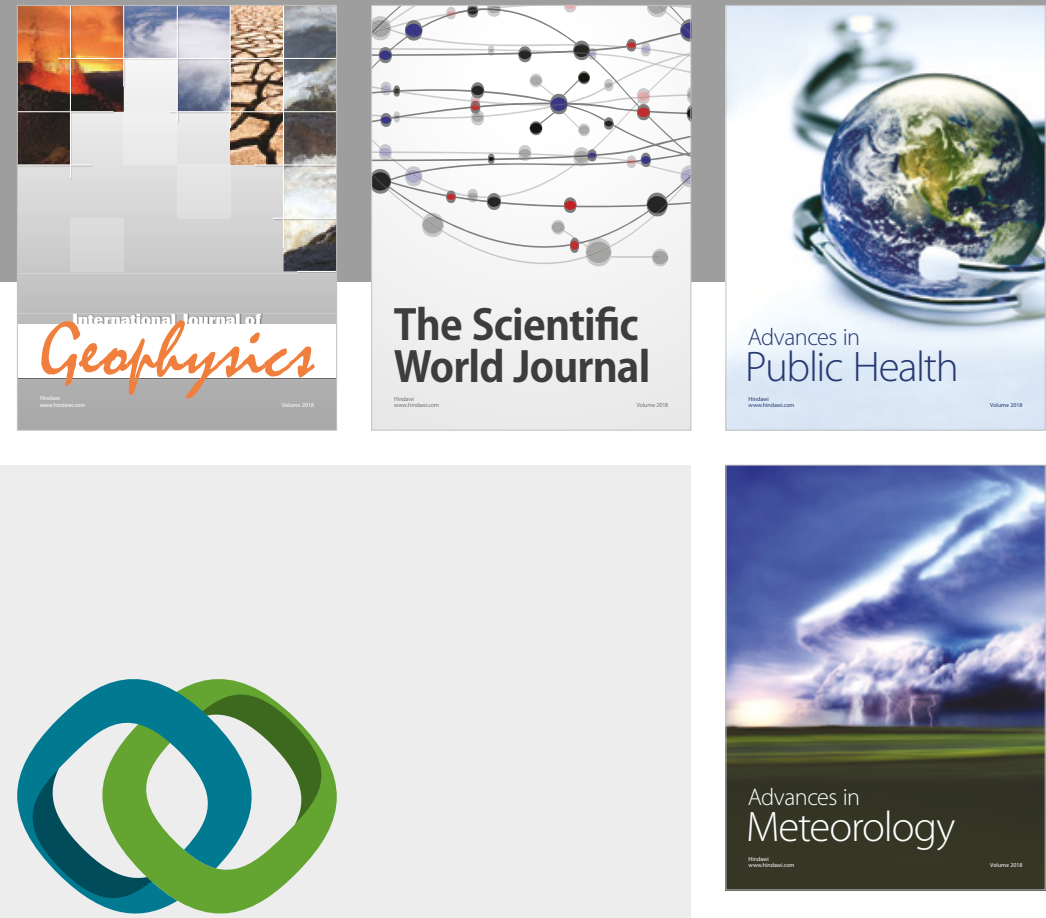

Advan

Public Health

\section{Hindawi}

Submit your manuscripts at

www.hindawi.com
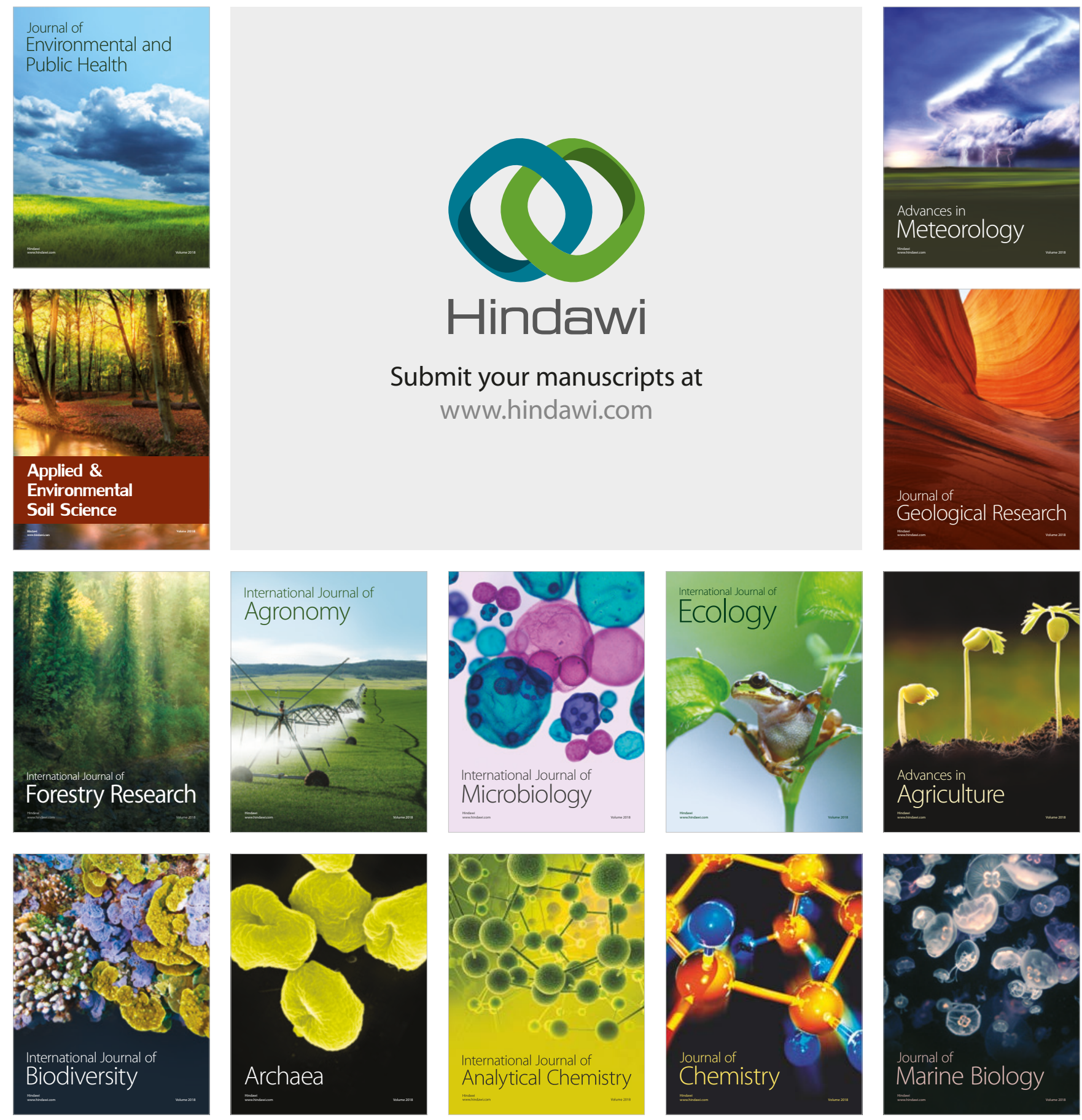